\title{
Conscious, Explicit Memory, Implicit Memory, and Instincts as the Four-Component Mind for the Mental Origins of Psychotherapy and Personality
}

\author{
Dingyu Chung \\ Utica, MI, USA \\ Email: dy_chung@yahoo.com
}

How to cite this paper: Chung, D.Y. (2020) Conscious, Explicit Memory, Implicit Memory, and Instincts as the Four-Component Mind for the Mental Origins of Psychotherapy and Personality. Journal of Behavioral and Brain Science, 10, 471-516. https://doi.org/10.4236/jbbs.2020.1011030

Received: October 1, 2020

Accepted: November 27, 2020

Published: November 30, 2020

Copyright $\odot 2020$ by author(s) and Scientific Research Publishing Inc. This work is licensed under the Creative Commons Attribution International License (CC BY 4.0).

http://creativecommons.org/licenses/by/4.0/

\begin{abstract}
This paper proposes that conscious, explicit memory, implicit memory, and instincts constitute the four-component mind for the mental origins of psychotherapy and personality. The mental origin of the personality theories including the big five personality traits, the MBTI, the social style model, the Hofstede's cultural dimensions, and the Schwartz's theory of basic human values is from the unconscious instincts (the six social and three mental protective instincts). The three mental protective instincts that contain the three instinctive countermeasures against the three adversities are hyperactivity countermeasure against danger, phobia countermeasure against unfamiliarity-uncertainty, and comforter countermeasure against hardship. Each countermeasure is regulated (moderated) by a regulator to minimize overactive countermeasure as physical regulator to minimize overactive immunity in physical immune system. Severe adversities and ineffective regulators over-activate protective countermeasures to generate overactive countermeasures as overactive hyperactivity, overactive phobia, and overactive comforter, corresponding to dramatic-impulsive cluster, anxious-fearful cluster, and odd-eccentric cluster, respectively for personality-mental disorders in the DSM-5. Such disordered behavioral habits are stored in unconscious implicit memory which generates disordered thought patterns in pre-conscious explicit memory. For psychotherapy, cognitive behavioral therapy (CBT) normalizes disordered thought patterns in explicit memory to normalize disordered behavioral habit memory in implicit memory through the repetitive training in normalizing thought patterns, feelings, and behaviors. For psychotherapy, mindfulness meditation strengthens conscious attention (working memory) to normalize disordered behavioral habit memory through the
\end{abstract}


repetitive training in directing conscious attention to the breath or body. In conclusion, the mental origin of personality-mental disorders is from the overactive mental protective instincts. The mental origin of psychotherapy is from therapeutic implicit memory and conscious attention for $\mathrm{CBT}$ and mindfulness meditation, respectively. The mental origin of personality is from the unconscious instincts. Therefore, the four-component mind of conscious, explicit memory, implicit memory, and instincts explains the origin, the storage, and the normalization of personality-mental disorders for psychotherapy, and provides the mental origin of personality.

\section{Keywords}

Conscious, Explicit Memory, Implicit Memory, Instincts, Mind, Psychotherapy, Personality

\section{Introduction}

Freud categorized the mind in three parts consisting of the conscious mind, the pre-conscious mind, and the unconscious mind [1]. Conscious contains all that we sense, think, remember, feel, and wish at any given moment. Preconscious contains what is readily available to the conscious mind, although not currently in use. Unconscious is defined as a reservoir of feelings, thoughts, urges, and memories outside of conscious awareness. Most of the contents of unconscious are considered unacceptable or unpleasant which are repressed or held out of awareness because they are simply too threatening. Unconscious also contains drives, urges, and instincts. To Freud, sexual instinct is the dominant instinct [2]. Freud believed that sometimes these hidden desires and wishes make themselves known through dreams [3] and free associations.

In Freudian psychoanalysis (PA) [1], all people possess unconscious instincts, thoughts, feelings, and memories. Severe conflicts can produce various defend mechanisms, such as repression, sublimation, and regression, to hide such severe conflicts in unconsciousness, resulting in mental problems. PA focuses on bringing the hidden conflict in a client from unconscious to conscious, where the client can heal emotional wounds and shift unhealthy relationship patterns and behaviors. PA is often relatively long-term in terms of several months or years. This approach is a common choice for individuals who feel that they might benefit from gaining insight into themselves instead of a pressing issue or condition.

This paper proposes the four-component mind of conscious, explicit memory, implicit memory, and instincts based on neuroscience for psychotherapy and personality. With respect to the Freudian three-component mind of conscious, preconscious, and unconscious, unconscious roughly corresponds to instincts and implicit memory, and preconscious roughly corresponds to explicit memory. However, in the four-component mind, unconscious instincts are not domi- 
nated by sexual instinct, unconscious implicit memory is not a storage place for hidden desires and wishes by repression, and conscious reconstructs rather than merely retrieves from whatever available in preconscious explicit memory. Like in the Freudian three-component mind, conscious in the four-component mind is a small part of mind.

Unconscious implicit memory is a form of long-term memory that doesn't require any conscious retrieval. Implicit memory includes procedural memory, priming, and conditioning [4]. Procedural memory is the knowledge and skill of how to perform various tasks, such as riding a bike. Priming involves how a past experience increases the accuracy or quickness of a response without consciously awareness of the past experience. Classical conditioning is the unconscious association of one thing with another, such as the unconscious association of a specific sound and salivation in Pavlov's dog. Implicit memory basically contains behavioral habit memory for behavioral habits. Personality-mental disorders are disordered behavioral habits, so disordered behavioral habit memory is in implicit memory.

Explicit memory consisting of episodic and sematic memories requires conscious retrieval. Conscious is controlled mostly by the sensory memory and short-term (working) memory in the prefrontal cortex. This paper proposes that for the survival of the normal mental state, explicit memory and conscious attention (working memory) automatically and instinctively become therapeutic explicit memory and therapeutic conscious attention to normalize disordered behavioral habit memory in implicit memory. The failure to normalize leads to the damage in explicit memory and conscious.

An evidence for mental disorder in implicit memory is shown in the study of implicit (procedural) and explicit memory in obsessive-compulsive disorder (OCD) [5]. OCD involves the overactive striatum which stores procedural memory as an implicit memory. In another study, the reduction of basal ganglia where implicit memory locates was found in major depressive disorder and bipolar disorder [6]. Mental disorders are derived from disordered behavioral habit memory in implicit memory.

In the study of explicit memory, Nairne et al. found that explicit memory has evolved for survival [7]. Short-terms (working) memory for conscious is necessary for explicit memory, so conscious attention in terms of working memory has also evolved for survival. Conscious attention as in mindfulness meditation is shown to enhance explicit memory [8]. Therapeutic explicit memory for the survival of the normal mental state is supported by the review of various studies of post-traumatic stress disorder (PTSD) and explicit memory functioning [9]. The review shows that it is likely that explicitmemory dysfunction is both a pre-existing risk factor for the development of PTSD as well as a consequence of the disorder. In other words, pre-existing neurocognitive deficits in explicit memory lead to an increased risk of PTSD. Explicit memory behaves as therapeutic memory to minimize the development of PTSD. The review also shows 
the failure to cure causes the damage in explicit memory.

In the study of a compensatory role for explicit memory in neurodevelopmental disorders [10], the evidence suggests that explicit memory indeed plays compensatory roles for specific language impairment, dyslexia, autism spectrum disorder, Tourette syndrome, and obsessive-compulsive disorder. Explicit memory is a therapeutic memory for specific language impairment, dyslexia, autism spectrum disorder, Tourette syndrome, and obsessive-compulsive disorder. Various defend mechanisms as described in PA are the automatic and instinctive self-help therapeutic mechanisms from explicit memory that fail to normalize disordered behavioral habit memory in implicit memory.

For psychotherapy, cognitive behavioral therapy (CBT) normalizes disordered thought patterns in explicit memory to normalize disordered behavioral habit memory in implicit memory through the repetitive training in normalizing thought patterns, feelings, and behaviors. CBT focuses on finding practical, skills-based solutions to present-day problems. CBT focuses on the recognitions of negative (irrational) thought patterns and the changes of such negative thoughts, behaviors, and feelings through concrete skills. CBT does not locate the root cause of the problem. CBT often entails homework assignments to master the skills to change negativity into positivity. The patient's active participation in therapy is a key principle in CBT. Without it, this goal-oriented and problem focused approach would not be effective. CBT is often short-term in terms of 2 - 3 months. The involvement of explicit memory in CBT is supported by Rachel Ariella Bartfeld who found that CBT leads to the hippocampal growth in explicit memory [11].

Mindfulness meditation was shown to enhance working memory in conscious [12]. Mindfulness-based treatments have shown efficacy across a wide range of psychiatric disorders, including major depressive disorder [13] [PTSD [14], and anxiety disorders [15]. The failure to cure leads to the damages to conscious as in the cases of schizophrenia [16] and PTSD [17].

In the four-component mind for psychotherapy, instincts consist of the six social instincts for the formation of society and the three protective instincts against adversities [18]. The six social instincts are kinship instinct based on commitment, alliance instinct based on reciprocity, division of labor based on interdependence, reproductive (sexual) instinct based on propagation, generativity instinct based on multigenerational care, and boundary instinct based on the boundary between ingroup and outgroup. The three egos based on boundary instinct are dualistic territorial ego with rigid boundary, competitive-independent individualistic ego without rigid boundary and with extended outgroup, and cooperative-relational collectivistic ego without rigid boundary and with extended ingroup.

The three protective instincts that contain the three instinctive countermeasures against the three adversities are hyperactivity countermeasure against danger, phobia countermeasure against unfamiliarity-uncertainty, and comfor- 
ter countermeasure against hardship. Each countermeasure is regulated (moderated) by a regulator to minimize overactive countermeasure as physical regulator to minimize overactive immunity in physical immune system. Severe adversities and ineffective regulators over-activate protective countermeasures to generate the disordered behavioral habit memory in implicit memory as personality-mental disorders, such as post-traumatic stress disorder (overactive hyperactivity) against severe danger, anxiety disorder (overactive phobia) against severe unfamiliarity-uncertainty, and schizophrenia (overactive comforter) against severe hardship. The disordered behavioral habit memory generates disordered thought patterns in explicit memory.

The five stages in Freudian psychosexual development are oral, anal, phallic, latency, and genital, representing the fixation of sexual instincts on a different area of the body in different ages. In different stages, different areas of the body become important as sources of potential frustration, pleasure or both. For the four-component mind, the developmental psychology is the identity-adversity development based on the social instincts and the protective instincts [19].

Personality theories and psychotherapy are unavoidably linked. This paper proposes the instinctive personality theory based on the social instincts and the protective instincts. The popular personality theories including the big five personality traits, the MBTI, the social style model, the Hofstede's cultural dimensions, and the Schwartz's theory of basic human values are derived from the instinctive personality theory.

According to Freud, dream is the latent content of the dream explains the hidden meaning of one's unconscious thoughts, drives, and desires. The unconscious mind actively suppresses what can be revealed from the latent content of dream. In the four-component mind, the content of dream explains reactivation, consolidation, and stabilization of waking memories during sleep.

In the following sections of the paper, the six social instincts, the protective instincts, memories, the identity-adversity development, the instinctive personality theory, wakefulness and sleep, and psychotherapy and mental health maintenance will be discussed.

\section{The Social Instincts}

In the four-component mind for psychotherapy, instincts consist of the six social instincts for the formation of society and the three protective instincts against adversities. The social instincts are derived from the social brain [20] [21] [22] which is the network of brain regions that are involved in understanding others. We are biologically hard-wired for interacting with others. The social brain is located mainly in the neocortex in the outmost layer of the brain. The neocortex is much larger in humans as compared to other primates and mammals of similar size. The social brain also involves the neurotransmitter/hormone system to provide a psychopharmacological platform for the cognitive component. The six social instincts are kinship based on commitment, alliance based on reciprocity, 
division of labor based on interdependence, reproductive (sexual) based on propagation, generativity based on multigenerational care, and boundary based on ingroup-outgroup.

\subsection{Kinship Instinct}

Kinship instinct benefits vulnerable children against neglect by forming kinship group [23] whose relations depend on commitment to a social group rather than reciprocal benefit of individuals. The origin of kinship instinct is the social group of caregivers and vulnerable children. For non-primate vertebrates, such as bird, the brain size is proportional to the duration and complexity of commitment in kinship instinct [24]. Birds form kinship and flock, not alliance. The neurotransmitter to promote family intragroup relation is oxytocin, so people feel good when they are with their kin.

\subsection{Alliance Instinct}

Alliance intragroup relation benefits vulnerable individuals against predation by forming an alliance group [20] [21] [22] whose relations depend on reciprocal benefit of individuals rather than commitment to a social group. The base of alliance intragroup relation is extensive and complex socialization. For primates, the brain size for alliance intragroup relation is proportional to the group size and the complexity of socialization. According to Dunbar, the proper group size based on the human brain size is around 150 [25]. Primates form kinship and alliance. The neurotransmitter to promote alliance intragroup relation is endorphins, so people feel good when they have alliances.

Hill and colleagues found that the hunter-gatherer bands in their dataset are not composed mainly of close kin [26]. Bands are mainly composed of individuals either distantly related by kinship and/or marriage or unrelated altogether. In their sample of 32 societies, primary kin generally make up less than $10 \%$ of a residential band. They found that hunter-gatherers display a unique social structure where 1) either sex may disperse or remain in their natal group, 2) adult brothers and sisters often co-reside, and 3) most individuals in residential groups are genetically unrelated. Therefore, in terms of the social instincts, alliance instinct to form alliance group is much more important than kinship instinct to form kinship group for the human hunter-gatherer band social structure.

\subsection{Division of Labor Instinct}

Division of labor intragroup relation benefits vulnerable specialists against handicaps by forming a specialist group from specialists whose relations depend on existential interdependence [27]. The early hominins formed the interdependent specialist groups consisting of the forest group of homemaker-forager for women and children and the woodland group of explorer-forager for men in the mixed forest-woodland habitat [28]. The handicap was the feet which were still 
suitable for climbing trees, and not suitable to walk long distance and run fast on the ground especially for pregnant women and small children in woodland area. Later, the division of labor became gatherer-hunter in open savanna habitat. This division of labor intragroup relation is called eusociality [29] characterized by the division of labor as in eusocial bees and ants. Homo sapiens are also eusocial [27].

Such interdependent specialists group produced theory of mind (mind-reading) that recognizes that the others exist to think for themselves [30]. Theory of mind is derived from theory of specialty (specialty-reading) in interdependent specialists group where each specialist has its own specialty of work and work plan. In theory of specialist, each specialist must recognize that each specialist has its own specialty different from the specialties of other specialists, and each specialist has its own work plan distinctively different from the work plans of other specialists. To work together interdependently, all specialists must have theory of specialist in order to avoid overlapping unproductively and dangerously each other's work. Theory of specialty turned into theory of mind where specialty was replaced by the mind of each person. In theory of generality, each generalist does not need to distinctively recognize the types of work and work plans of other generalists, because they are not distinctively different. As a result, theory of generality does not turn into theory of mind. Only humans have robust theory of mind [31]. Theory of mind instinct is essentially equivalent to division of labor instinct.

\subsection{Reproductive (Sexual) Instinct}

The fundamental function of reproductive (sexual) instinct is to propagate the species. To Freud, sexual instinct is equivalent to pleasurable instinct [2], and sexual instinct does not originally serve the purposes of reproduction at all, but has as its aim the gaining of particular kinds of pleasure. It manifests itself in this way in human infancy, during which it attains its aim of gaining pleasure not only from the genitals but from other parts of the body (the erotogenic zones).

In a functional neuroimaging study of sexual arousal, a peripheral organ does not seem to be an essential part of the determinants of sexual arousal, and it is rather the central processing of visual or genital stimuli that gives to these stimuli their sexually arousing and sexually pleasurable character [32]. For male libido, proper amounts of testosterone, dopamine, and glutamate enhance male libido, while serotonin inhibits male libido [33] [34]. Oxytocin has been known for its roles in female reproduction for orgasm, bonding, childbirth, breastfeeding, and maternal behaviors [35].

\subsection{Generativity Instinct}

Multigenerational relation benefits future generations by forming multigenerational group whose relations depend on generativity [36] [37] [38] [39]. Unlike great apes, infertile women who have long life after menopause allows multiple 
generations to live together. During the human evolution, some unique variants, such as ApoE3, in genes were evolved to lower the risk of most aging diseases [40]. Increased longevity through generativity was proved by the computer simulation of increased longevity through grandmothering [41].

The caring of infertile women after menopause for their grandchildren and great-grandchildren is the base of legacy. Used in the psychology of Erik Erikson [36], generativity that exists only in humans involves the care and concern from older people to establish and guide next generation [37] as the legacy to the whole society [38]. In the monogamous hunter-gatherer society during human evolution, individuals (monogamous couples) after menopause became infertile. Such infertile individuals at the age of menopause were likely to be leaders-mentors with abundant knowledge, experiences, and social connections, even though physically they were weaker than young adults. After menopause, these infertile leaders-mentors could not have dependent children, so without dependent children, the infertile leaders-mentors were generous in protecting next generation instead of their own dependent children.

\subsection{Boundary Instinct}

Boundary instinct is based on the boundary that separates ingroup and outgroup. In ingroup, individuals share similar interests and attitudes, and produce instinctive feeling of ingroup favoritism as solidarity, community, and exclusivity [42]. Individuals in outgroup outside one's own group are different in interests and attitudes, and produce instinctive feeling of outgroup derogation as inferiority and alienation. Morality is defined as proper behavior. Morality toward ingroup is opposite of morality toward outgroup [43]. Ingroup morality is cooperative connection derived from instinctive ingroup favoritism. Outgroup morality is zero-sum aggressive competition derived from mutual outgroup derogation among social groups. According to evolutionary psychologists, this discrimination between connective ingroup morality and competitive outgroup morality has evolved because it enhances group survival in terms of instinctive cooperative connection toward ingroup and instinctive aggressive competition toward outgroup [44].

Such attitudes toward ingroup and outgroup are instinctive, appearing even in babies at few months old. As shown in the Infant Cognition Center at Yale University [45], babies prefer the objects (such as dolls) as ingroup objects that have similarities with the babies rather than the objects as outgroup objects that do not have similarities with the babies. Babies also prefer the objects with helpful behavior to the objects with bully behavior. However, babies prefer the doll that bullies another doll that is not like the babies. In other words, even though babies dislike the individuals who harm other individuals, babies prefer the individuals who harm outgroup individuals that are not like the babies. The zero-sum competitive attitude toward outgroup is instinctive. On the basic level, the relation toward outgroup is discrete without connection, while the relation 
toward ingroup is connective with connection.

This bimodal ingroup and outgroup relate to the bimodal proactive aggression and reactive aggression, respectively [46]. Proactive aggression generally results from the conflict toward ingroup, while reactive aggression generally comes from the conflict toward outgroup [47]. The distinction between the two types is centered on the aims of aggression. Proactive aggression aiming at outgroup involves a purposeful planned attack with an external or internal reward as a goal. It is characterized by attention to a consistent target, and often by a lack of emotional arousal. By contrast, reactive aggression aiming at ingroup is a response to a threat or frustrating event, with the goal being only to remove the provoking stimulus. Proactive aggression toward outgroup is characterized by low physiological arousal, a lack of social communication, and targeting of vulnerable body parts, because outgroup is basically a discrete group without any connection to the aggressor. By contrast, reactive aggression toward ingroup is associated with high physiological arousal and communication of intent including threats, because ingroup is basically a connective group with connection with the aggressor. The two types are sometimes easy to distinguish. For example, when two animals compete with steadily escalating intensity, as frequently occurs in fights over food or mates, aggression is typically reactive without any proactive elements.

Tulogdi et al. [48] found that proactive aggression was associated with innervation of the central and basolateral amygdala, the lateral hypothalamus, and the ventrolateral periaqueductal gray. By contrast, reactive aggression was associated with the medial amygdala, the mediobasal hypothalamus, and the dorsal periaqueductal gray [49]. The results of Tulogdi et al. indicate the existence of two different pathways in a key neural circuit underlying aggression.

Basically, ingroup represents cooperation-relational, while outgroup represents competition-independence. The mind structure for ingroup-outgroup-boundary results in three different egos, including dualistic territorial ego for ingroupoutgroup with a rigid boundary between ingroup and outgroup, competitive-independent individualistic ego for extended competitive-independent outgroup without a rigid boundary between ingroup and outgroup, and cooperative-relational collectivistic ego for extended cooperative-relational ingroup without a rigid boundary between ingroup and outgroup. Humans with fairly distinctive boundary in the original human society were evolved with territorial ego which has a high propensity for proactive aggression toward outgroup and a low propensity for reactive aggression toward ingroup.

On the other hand, chimpanzee and bonobo have fission-fusion society with overlapping social groups in which the social group size and composition change throughout the year with different activities and situations. As a result they do not have rigid boundary between ingroup and outgroup. The natural habitats of chimpanzees and bonobos are separated by Congo River. The poor natural habitat where chimpanzees live has much higher resource competition than the rich natural habitat where bonobos live. Therefore, the principal ego of chim- 
panzees is competitive-independent individualistic ego adaptive to competition, while the principal ego for bonobos is cooperative-relational ego adaptive to cooperation. Individualistic ego in chimpanzee is shown in a high propensity for proactive aggression and reactive aggression, while collectivistic ego in bonobo is shown in a low propensity for proactive aggression and reactive aggression. Compared with chimpanzees and bonobos, humans have a high propensity for proactive aggression like chimpanzees and unlike bonobos, and a low propensity for reactive aggression unlike chimpanzees and like bonobos [46]. In bonobos, no proactive aggression leading to intergroup killings has been observed [50]. Proactive aggression toward conspecifics is accordingly much more common in chimpanzees and humans than in bonobos, where it is infrequent or absent. The highly aggressive behaviors of adult male chimpanzees can be described as male warriors [51]. Because of division of labor relation based on interdependence in humans, chimpanzees and bonobos without division of labor relation both show more reactive aggression toward ingroup than humans. The human low propensity for reactive aggression toward ingroup is shown in human small canine teeth unlike large canine teeth in other animals for ingroup fighting. The two important traits that distinguish early hominins from other apes are bipedalism and small canine teeth [28]. The egos in apes are listed in Table 1. The rise of civilization with mostly flexible boundary has changed human egos into all three egos as territorial, individualistic, and collectivistic egos for humans.

\section{The Protective Instincts}

The physical immune system is a physical protective system against pathogens (harmful invaders), whereas the mental immune system [18] is a mental protective system against adversities such as hardship, danger, and unfamiliarity-uncertainty. The overactive immune system without proper immune system regulators produces physical overactive immunity as physical disorders, whereas the overactive mental immune system without proper mental immune system regulators [18] produces overactive mental immunity as personality-mental disorders. Therefore, the physical immune system correlates to the mental immune system. The mental immune system and the physical immune system interact.

Table 1. Egos in apes.

\begin{tabular}{lccccc}
\hline Ego/boundary & attribute & Intergroup & $\begin{array}{c}\text { Proactive } \\
\text { aggression }\end{array}$ & $\begin{array}{c}\text { Reactive } \\
\text { aggression }\end{array}$ & $\begin{array}{c}\text { Species (in gene } \\
\text { without culture) }\end{array}$ \\
Territorial/rigid & Dualistic & $\begin{array}{c}\text { ingroup- } \\
\text { outgroup }\end{array}$ & high & low & human \\
$\begin{array}{c}\text { Individualistic/ } \\
\text { flexible competitive-independent }\end{array}$ & $\begin{array}{l}\text { extended } \\
\text { outgroup }\end{array}$ & high & high & chimpanzee \\
$\begin{array}{c}\text { Collectivistic/ } \\
\text { flexible }\end{array}$ cooperative-relational & $\begin{array}{c}\text { extended } \\
\text { ingroup }\end{array}$ & low & low & bonobo \\
\hline
\end{tabular}


For example, excessive chronic production of inflammatory cytokines from the overactive physical immune system has been linked to depression resulted from the overactive mental immune system [52]. It seems that modification of chronic inflammation also improves the mental state of patients suffering from chronic overactive mental immune system, such as depression [53]. The physical immune system and the mental immune system against pathogens or adversities have regulators to regulate immune systems, and the two systems interact.

The mental immune system involves both the brain cell network and the endocrine system. The mental immune system against adversity consists of the mental countermeasure to overcome adversity and the persistent mental focus to focus in adversity. The response of the mental countermeasure is fast, whereas the response of the mental focus is slow. The mental countermeasure-focus is the mental immune system against adversity. One example of the countermeasure-focus systems is the hyperactivity-stress axis as the sympathetic adreno medullary (SAM) axis-hypothalamic-pituitary-adrenal (HPA) axis against danger as the adversity. The main neurotransmitters from the SAM-HPA are adrenaline-cortisol. This paper proposes that the mental immune system includes comforter countermeasure against hardship adversity to maintain durability, hyperactivity countermeasure against danger adversity to maintain existence, and phobia countermeasure against unfamiliarity-uncertainty adversity to maintain adaptability.

In the balanced mental immune system, the mental countermeasure is balanced by the mental immune system regulator [52], in the same way as the countermeasure in the physical immune system is balanced by the immune system regulator that constrains the activity of the countermeasure. In the inherited highly imbalanced mental immune system without the proper mental immune system regulator, excessive adversity and mental countermeasure generate overactive countermeasure as the overactive mental immune system, resulting in overactive mental immunity and mental autoimmune disorders as personality-mental disorders against ubiquitous perceived adversity, in the same way as that the overactive immune system against ubiquitous detected invaders, harmful and harmless.

Personality disorders in the DSM-5 (the Diagnostic and Statistical Manual of Mental Disorders, Fifth Edition) [54] are divided into odd-eccentric cluster (schizotypal, paranoid, and schizoid), dramatic-impulsive cluster (histrionic, antisocial, borderline, and narcissistic), and anxious-fearful cluster (dependent, obsessive-compulsive, and avoidant). This paper proposes that personality disorders are divided into odd-eccentric cluster from the overactive comforter against ubiquitous perceived hardship, dramatic-impulsive cluster from the overactive hyperactivity against ubiquitous perceived danger, and fearful-anxious cluster from the overactive phobia against ubiquitous perceived unfamiliarity-uncertainty. The mental immune system and personality disorders are shown in Table 2. 
Table 2. The mental immune system and personality disorders.

\begin{tabular}{cccccc}
\hline Countermeasure & Adversity & Purpose & $\begin{array}{c}\text { Countermeasure } \\
\text { neurotransmitter }\end{array}$ & $\begin{array}{c}\text { Regulator } \\
\text { neurotransmitter }\end{array}$ & Personality disorder \\
\hline Comforter & hardship & maintain durability & endorphins & $\begin{array}{c}\text { dopamine } \\
\text { antagonist }\end{array}$ & odd-eccentric cluster \\
Hyperactivity & danger & maintain existence & adrenaline & $\begin{array}{c}\text { serotonin } \\
\text { agonist }\end{array}$ & $\begin{array}{c}\text { dramatic-impulsive } \\
\text { cluster }\end{array}$ \\
Phobia & unfamiliarity-uncertainty & maintain adaptability & adrenaline-glutamate & $\begin{array}{c}\text { serotonin-GABA } \\
\text { agonist }\end{array}$ & fearful-anxious cluster \\
\hline
\end{tabular}

\subsection{Comforter against Hardship and Odd-Eccentric Cluster}

As serious hindrance to durable life, hardship as the adversity brings about instinctive comforter as the mental countermeasure to overcome hardship as shown by the emergence of endorphins for the maintenance of durability. Comforter is manifested as the painless high while in stress for a long time as runner's high [55] while running for a long time. Runner's high allows an exhausted runner to continue running at normal speed. Comforter can be also as imaginary comforter (fantasy). Imaginary comforter as imaginary companion often occurs during childhood [56] to overcome hardship [57]. Up to two-thirds of children have imaginary companions, and some children develop entire imaginary worlds for their imaginary companions.

The mental immune system regulator constraining comforter (endorphins) is dopamine (neurotransmitter for pleasure) antagonist. Excessive hardship and comforter in the inherited highly imbalanced system without the proper dopamine antagonist generate overactive comforter as the overactive mental immune system, resulting in the mental inflammation as odd-eccentric cluster for personality-mental disorders against ubiquitous perceived hardship as shown by excessive dopamine in the prefrontal cortex. In terms of neurotransmitters, the failure of constraining endorphins (comforter) by dopamine antagonist as the mental immune system regulator results in the mental inflammation as odd-eccentric cluster.

In the overactive mental immune system, the perception in search for potential adversity is overactive to produce ubiquitous perceived adversity [58]. The emotion in response to adversity is exaggerated to produce all-or-nothing thinking without nuance in dealing with adversity. Therefore, the symptoms of odd-eccentric cluster are overactive imaginary comforter (fantasy), ubiquitous perceived hardship, and all-or-nothing thinking without nuance in dealing with hardship. Odd-eccentric cluster personality disorders include schizotypal, paranoid, and schizoid. Overactive stress-comforter is more extreme in mental disorders than in personality disorders. In schizophrenia as a mental disorder, the extremely overactive imaginary comforter is hallucination where overactive fantasy becomes visible and audible. Schizophrenia is overactive comforter against ubiquitous perceived hardship. 


\subsection{Hyperactivity against Danger and Dramatic-Impulsive Cluster}

As catastrophe to existence of life, danger as the adversity brings about instinctive hyperactivity (the fight-or-flight response) as the mental countermeasure to overcome danger as shown by the emergence of adrenaline. Hyperactivity is manifested as the rush of energy. The mental immune system against danger is the hyperactivity with adrenaline. The mental immune system regulator is serotonin agonist. Excessive danger and hyperactivity in the inherited highly imbalanced system without proper serotonin agonist generate overactive hyperactivity-stress as the overactive mental immune system, resulting in the mental inflammation and mental autoimmune disorder as dramatic-impulsive cluster for personality-mental disorder against ubiquitous perceived danger as shown by deficient serotonin. In terms of neurotransmitters, the failure of constraining adrenaline (hyperactivity) by serotonin agonist as the mental immune system regulator brings about the mental inflammation and mental autoimmune disorder as dramatic-impulsive cluster.

The symptoms of dramatic-impulsive cluster are overactive hyperactivity, ubiquitous perceived danger, and all-or-nothing thinking without nuance in dealing with danger. Dramatic-impulsive cluster personality disorders include histrionic, antisocial, borderline, and narcissistic. With the extreme depreciation of self, self-destructive depression is a mental autoimmune disorder against ubiquitous perceived danger in terms of ubiquitous perceived defects and flaws in self [58]. Bipolar disorder (manic-depression) possesses the mental inflammation (manic) and the mental autoimmune disorder (depression) alternatively. Post-traumatic stress disorder is overactive hyperactivity against ubiquitous perceived danger.

\subsection{Phobia against Unfamiliarity-Uncertainty and Fearful-Anxious Cluster}

As the deviation from familiar-certain traditional adaptive way of life, unfamiliarity-uncertainty as the adversity brings about instinctive phobia as the mental countermeasure against moving to unfamiliar-uncertain way of life to maintain familiar-certain adaptive way of life as shown by the emergence of adrenaline-glutamate (Glutamate is the active neurotransmitter to think about fear consciously). Normally, familiar-certain tradition provides the reliable way to live, so the maintenance of adaptability is important for survive. Phobia is manifested as a rush of extreme fear. The mental immune system against unfamiliarity-uncertainty is phobia with adrenaline-glutamate.

The mental immune system regulator is serotonin-GABA (gamma amino butyric acid) agonist to balance adrenaline-glutamate. Excessive unfamiliarity-uncertainty and phobia in the inherited highly imbalanced system without proper serotonin-GABA agonist generate overactive phobia as the overactive mental immune system, resulting in the mental inflammation as fearful-anxious cluster in personality disorders against ubiquitous unfamiliarity-uncertainty as 
shown by deficient serotonin-GABA. In terms of neurotransmitters, the failure of constraining adrenaline-glutamate (phobia) by serotonin and GABA agonist as the mental immune system regulator results in the mental inflammation as fearful-anxious cluster. The symptoms are overactive phobia, ubiquitous perceived unfamiliarity-uncertainty, and all-or-nothing thinking without nuance in dealing with unfamiliarity-uncertainty. Fearful-anxious cluster personality disorders include dependent, avoidant, and obsessive-compulsive. Overactive phobia-stress is more extreme in mental disorders than in personality disorders. Panic disorder and generalized anxiety disorder are overactive phobias against ubiquitous perceived unfamiliarity-uncertainty.

\subsection{Personality-Mental Disorders from Egos}

Personality disorders in the DSM-5 [54] [59] has three personality disorder clusters, each of which have three or more different disorders as odd-eccentric cluster for schizotypal, paranoid, and schizoid, dramatic-impulsive cluster for histrionic, antisocial, borderline, and narcissistic-antisocial, and anxious-fearful cluster for dependent, obsessive-compulsive, and avoidant. The three or more personality-mental disorders in each cluster represents disorders from dualistic territorial ego, competitive-independent individualistic ego, and cooperative-relational ego as in Table 3.

Table 3. Personality/mental disorders by egos.

\begin{tabular}{|c|c|c|c|c|c|c|}
\hline \multirow[t]{2}{*}{ 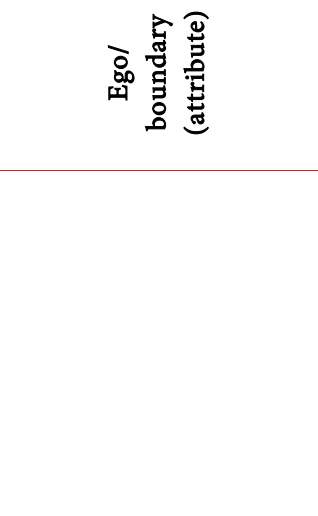 } & \multicolumn{3}{|c|}{ 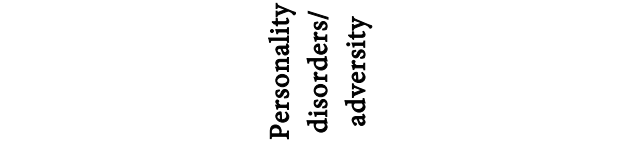 } & \multicolumn{3}{|c|}{ 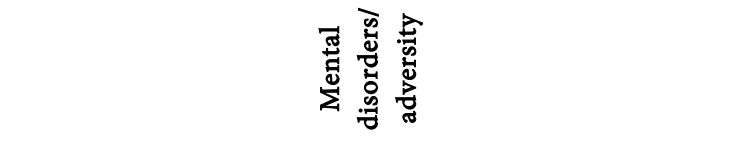 } \\
\hline & 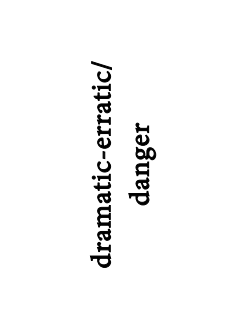 & 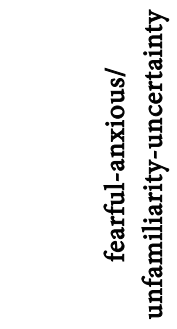 & 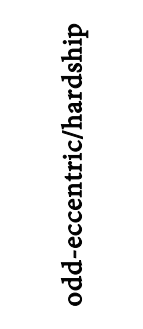 & 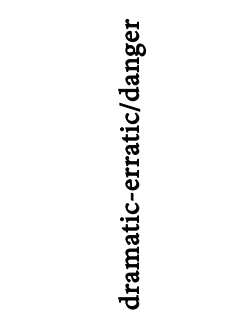 & 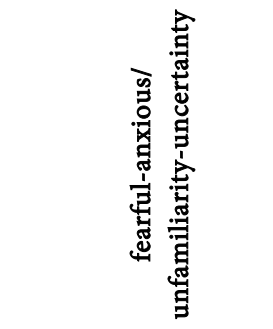 & 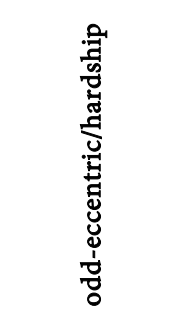 \\
\hline Territorial/rigid (dualistic) & borderline & obsessive-com & paranoid & bipolar & $\begin{array}{l}\text { obsessive-compulsive } \\
\text { disorder (OCD) }\end{array}$ & schizophrenia \\
\hline $\begin{array}{l}\text { Individualistic/ } \\
\text { flexible } \\
\text { (competitive-independent) }\end{array}$ & $\begin{array}{l}\text { Narcissistic } \\
\text { antisocial }\end{array}$ & avoidant & schizoid & $\begin{array}{l}\text { impulse control } \\
\text { disorders, } \\
\text { trauma-related } \\
\text { disorders, ADHD, } \\
\text { mania }\end{array}$ & $\begin{array}{l}\text { phobias, panic } \\
\text { disorder, generalized } \\
\text { anxiety disorder }\end{array}$ & $\begin{array}{l}\text { negative } \\
\text { schizophrenia, } \\
\text { dissociative } \\
\text { disorders, } \\
\text { somatic } \\
\text { symptom } \\
\text { disorders }\end{array}$ \\
\hline $\begin{array}{l}\text { Collectivistic/flexible } \\
\text { (cooperative-relational) }\end{array}$ & $\begin{array}{l}\text { histrionic (urgent } \\
\text { relation) }\end{array}$ & dependent & schizotypal & $\begin{array}{l}\text { depression (failed } \\
\text { relation) }\end{array}$ & $\begin{array}{l}\text { social anxiety, eating } \\
\text { disorders }\end{array}$ & $\begin{array}{l}\text { positive } \\
\text { schizophrenia }\end{array}$ \\
\hline
\end{tabular}




\subsubsection{Personality-Mental Disorders from Territorial Ego}

The disorders for dualistic territorial ego are characterized by sharp division between good-evil, and order-disorder, and high and low. Corresponding to territorial ego for hyperactivity against danger in dramatic-erratic personality disorder, borderline personality disorder tends to be impulsive, have unstable selfimage and intense relationships, and mood swings. The mental disorder is bipolar. Corresponding to territorial ego for phobia against unfamiliarity-uncertainty in fearful-anxious personality disorder, obsessive-compulsive concentrates in maintaining order over disorder. The mental disorder is obsessive-compulsive disorder. Corresponding to territorial ego for comforter against hardship in odd-eccentric personality disorder, paranoid concentrates in maintaining personal safety against imaginary hostile outside world. The mental disorder is schizophrenia with both positive schizophrenia and negative schizophrenia.

\subsubsection{Personality-Mental Disorders from Individualistic Ego}

The disorders for competitive-independent individualistic ego are extraordinarily aggressive and self-centered. Corresponding to individualistic ego for hyperactivity against danger in dramatic-erratic personality disorder, narcissistic against danger is self-centered and has an excessively elevated self-image, and antisocial is self-centered and excessively aggressive. The mental disorders are impulse control disorders, trauma-related disorders, ADHD, and mania. Corresponding to individualistic ego phobia against unfamiliarity-uncertainty in fearful-anxious personality disorder, avoidant avoids interpersonal contact and new activities. The mental disorders are phobias, panic disorder, and generalized anxiety disorder toward non-social things. Corresponding to individualistic ego for comforter against hardship in odd-eccentric personality disorder, schizoid avoid social activities, and has a limited range of emotional expression. The mental disorders are negative schizophrenia, dissociative disorders, and somatic symptom disorders.

\subsubsection{Personality-Mental Disorders from Collectivistic Ego}

The disorders for cooperative-relational collectivistic ego have extraordinary need and sensitivity for social relations. Corresponding to collectivistic ego for hyperactivity against danger in dramatic-erratic personality disorder, histrionic is characterized by an exaggerated display of emotions and by excessive attention seeking. The mental disorder is depression due to excessive disappointment in losing social relations. Corresponding to collectivistic ego for phobia against unfamiliarity-uncertainty in fearful-anxious personality disorder, dependent tends to display needy, passive, and clinging behavior, and have a fear of separation. The mental disorders are social anxiety, eating disorders with high sensitivity in social relations. Corresponding to collectivistic ego for comforter against hardship in odd-eccentric personality disorder, schizotypal has odd and inappropriate emotional responses to prevent social relations which they want. The mental disorder is positive schizophrenia. 


\section{Memories}

The four types of memories are sensory memory, short-term or working memory, explicit memory, and implicit memory. Conscious involves sensory memory and short-term memory. Explicit memory and implicit memory are long-term memory.

\subsection{Sensory Memory}

Sensory memory is a very brief memory last for three seconds or less. As soon as the information perceived by these organs reaches the part of the brain which processes the information, sensory memory is created. The purpose of sensory memory is to retain information long enough for it to be recognized. During this period of a second, information of the object is processed, and the brain recalls previous memory of the objects similar to it. This process of recalling enables the brain to identify the object and name it. If the object is something unique it gets stored or passed on to the comparatively longer storage memory type. While sensory memory may be very brief, it plays a critical role in the attention and memory processes.

\subsection{Short-Term (Working) Memory}

Short-term (or working) memory involves storing the processed information which passed the level of sensory memory. Short-term memory stores information passively, while working memory stores information actively to manipulate the information. Short-term memory lasts from few seconds to minutes. The capacity of items to remember is $4 \pm 1$ items [60]. In short-term memory stage, the priority list of the information is decided. Low priority information gets fade away as new information keeps entering the brain.

Short-term memory and long-term memory exist independently. People who lose the capacity of long-term memory can still recall items up to 30 seconds [61]. The prefrontal cortex is a store for short-term memory [62] [63]. The recent evidences show that the prefrontal cortex might be better understood not as a signature of memory storage per se, but as a top down signal that influences posterior sensory areas where the actual working memory representations are maintained.

\subsection{Explicit Memory}

Some pieces of information from short-term memory pass to long-term memory [64] consisting of explicit memory and implicit memory. Some pieces pass to long-term memory easily without conscious effort, but some pieces of information pass to long-term memory with conscious effort such as rehearsal. Unlike short-term memory, long-term memory has an almost unlimited span of storage for the whole lifetime.

Explicit (declarative) memory is the conscious storage and recollection of data. Explicit memory includes sematic memory and episodic memory. Sematic 
memory is the storage for words, concepts, or numbers, which is essential for the use and understanding of language. Episodic memory stores information that is encoded along a spatial and temporal plane [65].

The hippocampus on the temporal lobe of the brain consolidates the information from short-term to long-term memory for a period of three months or more after the initial learning. Without the hippocampus, new memories cannot be stored into long-term memory as in the case of patient Henry Molaison [66]. Memories are not stored in just one part of the brain. Different types are stored across different brain regions. For explicit memories, there are three important areas of the brain: the hippocampus, the neocortex and the amygdala. In humans, the neocortex is involved in higher functions such as sensory perception, generation of motor commands, spatial reasoning and language. Over time, information from certain memories that are temporarily stored in the hippocampus can be transferred to the neocortex as general knowledge for semantic memory. Amygdala on the temporal lobe creates sentimental and emotional responses which are then linked to the memories. This is particularly important because strong emotional memories (shame, joy, love, or grief) are difficult to forget. The permanence of these memories suggests that interactions between the amygdala, hippocampus and neocortex are crucial in determining the "stability" of a memory over time.

\subsection{Implicit Memory}

Unconscious implicit memory [4] is a form of long-term memory that doesn't require any conscious retrieval, while it takes a conscious effort to retrieve things from explicit memory. Implicit memory and explicit memory are in the different areas of the brain [67]. Implicit memory includes procedural memory, priming, and conditioning. Procedural memory is the knowledge and skill of how to perform various tasks, such as riding a bike. Priming involves how a past experience increases the accuracy or quickness of a response without consciously awareness of the past experience. Classical conditioning is the unconscious association of one thing with another, such as the unconscious association of a specific sound and salivation in Pavlov's dog.

The areas of the brain involved with implicit memory include the basal ganglia, the neocortex, and the cerebellum. In addition, the amygdala is involved in both explicit memory and implicit memory.

\subsection{Memories for Psychotherapy}

Implicit memory basically contains behavioral habit memory for behavioral habits. Personality-mental disorders are disordered behavioral habits, so disordered behavioral habit memory is in implicit memory. Evidence for disordered behavioral habit memory in implicit memory is shown in the study of procedural and explicit memory in obsessive-compulsive disorder (OCD) [5]. OCD involves the overactive striatum which stores procedural memory as an implicit 
memory. In another study, the reduction of basal ganglia where implicit memory locates was found in major depressive disorder and bipolar disorder [6]. Mental disorders are derived from disordered behavioral habit memory in implicit memory.

In the study of explicit memory, Nairne et al. found that explicit memory has evolved for survival [7]. However, McBride et al. found that survival as a primary purpose of memory cannot be detected in implicit memory [68]. Short-terms (working) memory for conscious is necessary for explicit memory, so conscious attention in terms of working memory has also evolved for survival. For the survival of the normal mental state, explicit memory and conscious attention (working memory) automatically and instinctively become therapeutic explicit memory and therapeutic conscious attention to normalize disordered behavioral habit memory. The failure to normalize leads to the damage in explicit memory and conscious.

To support therapeutic explicit memory, the review of post-traumatic stress disorder (PTSD) and explicit memory functioning [9] shows that it is likely that explicit memory dysfunction is both a pre-existing risk factor for the development of PTSD as well as a consequence of the disorder. Pre-existing neurocognitive deficits in explicit memory lead to an increased risk of PTSD. Explicit memory behaves as therapeutic memory to minimize the development of PTSD. The review also shows the failure to cure causes the damages in explicit memory. In the study of a compensatory role for explicit memory in neurodevelopmental disorders [10], the evidence suggests that explicit memory indeed plays compensatory roles for specific language impairment, dyslexia, autism spectrum disorder, Tourette syndrome, and obsessive-compulsive disorder. Explicit memory is a therapeutic memory for specific language impairment, dyslexia, autism spectrum disorder, Tourette syndrome, and obsessive-compulsive disorder. Various defend mechanisms as described in psychoanalysis are the automatic and instinctive self-help therapeutic mechanisms from explicit memory that fail to normalize disordered behavioral habit memory in implicit memory.

For psychotherapy, cognitive behavioral therapy (CBT) normalizes disordered thought patterns in explicit memory to normalize disordered behavioral habit memory in implicit memory through the repetitive training in normalizing thought patterns, feelings, and behaviors. The involvement of explicit memory in CBT is supported by Rachel Ariella Bartfeld who found that CBT leads to the hippocampal growth in explicit memory [11].

For psychotherapy, mindfulness meditation strengthens conscious attention to normalize disordered behavioral habit memory through the repetitive training in directing conscious attention to the breath or body. Conscious attention as in mindfulness meditation was shown to enhance explicit memory [8]. Mindfulness meditation was shown to enhance working memory in conscious [12]. Mindfulness-based treatments have shown efficacy across a wide range of psychiatric disorders, including major depressive disorder [13], PTSD [14], and an- 
xiety disorders [15]. The connection between mindfulness meditation and unconscious is supported by the experiments by Libet et al. [69] and Lush et al. [70] who showed that people who practice mindfulness meditation were more aware of their unconscious brain activity. Mindfulness meditation increases cortical thickness related to working memory [71]. The failure to cure leads to the damages to conscious as in the cases of schizophrenia [16] and PTSD [17].

\subsection{Freudian Id, Ego and Superego}

According to Freud psychoanalytic theory, the id is the primitive and instinctual part of the mind that contains sexual and aggressive drives and hidden memories, the super-ego operates as a moral conscience, and the ego is the realistic part that mediates between the desires of the id and the superego. In the four-component mind, id is basically the combination of instinct and implicit memory, superego is moral conscience expressed as rules in explicit memory, and ego is conscious that mediates between the id and the superego. Different societies have different moral consciences which can be in conflicts with instincts and behavioral habits. The conflicts between the id and the superego result in defend mechanisms in explicit memory.

\section{The Identity-Adversity Development}

Different theories of developmental psychology [72] have different stages of development. For examples, the Erik Erikson's eight stages of psychosocial development are infancy, toddlerhood, preschooler, schooler, adolescence, young adulthood, middle adulthood, and late adulthood [36]. According to the Erikson's psychosocial development, the ego develops through eight stages, each characterized by a basic psychosocial crisis, such as trust versus distrust and intimacy versus isolation. The acquisition of basic virtues, such as hope and love, results from successful completion of each stage. Basic virtues can be used by the ego to resolve subsequent crises. The five stages in Freudian psychosexual development are oral, anal, phallic, latency, and genital, representing the fixation of sexual instincts on a different area of the body in different ages. In different stages, different areas of the body become important as sources of potential frustration, pleasure or both.

This paper proposes identity-adversity development consisting of infancy, toddlerhood, childhood, and adulthood. Each stage has its principal identity, process of principal identity, attribute, process of attribute, principal adversity and countermeasure, and potential personality disorder in Table 4.

\subsection{Infancy (from Birth to 1.5-Year Old)}

Before birth, a fetus is basically a part of mother's body, and does not need any identity. After birth, an infant needs parents or primary caregiver as identity to help the infant to survive. To walk well, human bipedalism limits the size of the pelvis, resulting in the narrow birth canal. Human brains become too big to pass 
Table 4. The identity-adversity development.

\begin{tabular}{|c|c|c|c|c|c|}
\hline Stage/age & $\begin{array}{c}\text { Identity/ } \\
\text { Process/Self }\end{array}$ & Attribute/process & Social instincts & $\begin{array}{c}\text { Adversity/ } \\
\text { countermeasure }\end{array}$ & $\begin{array}{c}\text { Potential mental } \\
\text { problems }\end{array}$ \\
\hline $\begin{array}{l}\text { Infancy/ } \\
0-1^{1 / 2}\end{array}$ & $\begin{array}{l}\text { parent/parent } \\
\text { awareness/ } \\
\text { physical self }\end{array}$ & trust/trust in parent & family-boundary & danger/hyperactivity & $\begin{array}{l}\text { potential } \\
\text { dramatic-impulsive } \\
\text { cluster }\end{array}$ \\
\hline $\begin{array}{l}\text { Toddlerhood/ } \\
1^{1 / 2}-3\end{array}$ & $\begin{array}{l}\text { self/self-awareness/ } \\
\text { autonomous self }\end{array}$ & autonomy/exploration & & $\begin{array}{l}\text { unfamiliarity-uncertainty/ } \\
\text { phobia }\end{array}$ & $\begin{array}{l}\text { potential } \\
\text { fearful-anxious } \\
\text { cluster }\end{array}$ \\
\hline $\begin{array}{l}\text { Childhood/ } \\
3-18\end{array}$ & $\begin{array}{l}\text { other people/theory } \\
\text { of mind/diverse self }\end{array}$ & diversity/learning & division of labor & hardship/comforter & $\begin{array}{l}\text { potential } \\
\text { odd-eccentric cluster }\end{array}$ \\
\hline $\begin{array}{l}\text { Adulthood/ } \\
18-65+\end{array}$ & $\begin{array}{l}\text { society/ } \\
\text { sociality/social } \\
\text { self to establish } \\
\text { relations in diversity }\end{array}$ & $\begin{array}{l}\text { eusociality/interdependent } \\
\text { division of labor, } \\
\text { generativity, generosity }\end{array}$ & alliance-sexual-generativity & disintegration/integration & $\begin{array}{l}\text { potential } \\
\text { emergence of } \\
\text { personality-mental } \\
\text { disorders }\end{array}$ \\
\hline
\end{tabular}

through the birth canal when fully developed. A human newborn averages 369 $\mathrm{ml}$, and increases, during the first year of life, to about $961 \mathrm{ml}$, after which the growth rate declines. Brain volume peaks at the age of 40 after which it begins declining at 5\% per decade, speeding up around 70 [73]. Adult Homo sapiens have brains averaging $1200 \mathrm{ml}$ or more. Consequently, human infants are highly immature, unlike other great apes that have precocial newborns with the relatively mature brains.

The principal identity in infancy is parent. The process for the parent identity is parent-recognition. An infant feels more comfortable around the mother because not only is the mother's scent and voice familiar, but the infant also sees more of her all through the day, which is why infants recognize their mothers first. By the time infants turns three months old and can distinguish between various faces, the infant may become wary of strangers and unknown faces, and may start to cry to get attention from their parents. The attribute is trust, and the process is trust in parents. As discussed in Section 2.6., infant as young as 3 month old also has boundary instinct to distinguish ingroup and outgroup.

In the identity-adversity development, the principal adversity is danger. The social countermeasure against danger is kinship instinct to have family to protect infants. The mental immune countermeasure against danger is hyperactivity. Due to the highly immature brain at birth, the mental immune system is unregulated with unregulated hyperactivity against danger. For infants, all needs have to be met at once, and there is no delayed gratification. The way to express the countermeasure (hyperactivity) is relentless cry, the most powerful survival adaptation for infants. A human infant is born within a group of caring parents and relatives who inevitably response to baby's relentless cry. The infant mental immune system relies on committed parents. Without proper commitment from parents in terms of kinship instinct, the potential personality disorder that involves overactive hyperactivity against danger is dramatic-impulsive cluster. Empirical evidence suggests infants are only capable of implicit memory, so 
without explicit memory for the survival of the normal mental state, these early traumatic experiences in implicit memory can be severe [74].

\subsection{Toddlerhood (from 1.5 to 3 -Year Old)}

Toddlerhood starts at walking without the help of parent. The principal identity is self, and the process of self-identity is self-recognition. In a typical test for self-recognition, a toddler who has a red dot on the forehead touches the red dot when the toddler looks in the mirror. An infant does not have self-recognition, while a toddler at the age of about 18 months has self-recognition. Most animals, such as dogs, cats, and monkeys do not have self-recognition. The self is autonomous self. The principal attribute is autonomy, and the process is exploration.

In the identity adversity development, the principal adversity for a toddler to learn autonomy by exploration is unfamiliarity-uncertainty. The social countermeasure is still kinship instinct to guide toddlers. The mental immune countermeasure is phobia. Without mature regulator to moderate phobia, parental guidance is needed. Without proper parental guidance in terms of family instinct, the potential personality disorder that involves overactive phobia against unfamiliarity-uncertainty is fearful-anxious cluster.

\subsection{Childhood (3 - 18)}

Childhood starts at weaning at the age of about 3 for the human archaeological population whose weaning was about two to three years earlier than other great apes [75]. The earlier weaning allowed higher numbers of childbirths which made Homo sapiens more successful than other great apes in terms of population [76]. The early weaning also makes pre-juvenile age ( 3 to 5 ) difficult period without sufficient maturity and the full maternal care that diverts to a newborn sibling. Other great apes whose weaning occurs at the age of five or six do not have this difficult pre-juvenile age. Such early weaning is possible for humans because of theory of mind. A child at the age of about 4 years has theory of mind. Developmental psychologists define the theory of mind as the ability to take another person's viewpoint, and attribute mental state of mind to the others. No other animals have such robust theory of mind. Theory of mind allows children to know who and how other people to help them. The principal identity is other people who can help them through theory of mind. The self in childhood is diverse self to know different perspectives in different people.

In the identity-adversity development, the principal adversity is hardship due to early weaning. The social countermeasure is division of labor through theory of mind. Such division of labor is division of help to locate proper helpers through theory of mind. It is quite common in humans that older children take care of younger children. The mental immune countermeasure against hardship is comforter. A common comforter is imagination companion and/or imaginary self in the imaginary world. Up to two-thirds of children between the ages of 3 and 8 have imaginary companions [56]. Without full maternal care and sufficient maturity, they need imaginary companions to provide comfort in times of 
stress, boredom, and loneliness, to help them make sense of the adult world, and to overcome traumatic experiences. Taylor feel imaginary companions are common among children and are part of normal social-cognitive development [77]. The potential personality disorder that involves overactive comforter against hardship is odd-eccentric cluster.

\subsection{Adulthood (18 - 65+)}

Normally, an adult starts to pursuit higher learning such as college education and career at the age of 18 . In the hunter-gatherer society, the average age for the first childbirth is 19 . Young adults in twenties until mid to late 30 s are at the peak of physiological development including reproductive system, motor ability, strength, and lung capacity. After mid to late 30s, these systems start a slow and gradual decline to show signs of aging.

Basically, adulthood starts from the entrance into society and the beginning of serious social responsibility. The childhood's playfulness and affectation about diversity cannot deal with real social relations, social problems, and social responsibility. It is necessary to find real relations in diverse perspectives in the highly connected diverse society. The end of diverse childhood leads to the start of social adulthood. The principal identity in adulthood is society, and the process for the society-identity is sociality to establish relations in diversity. Sociality involves the mature social brain [39]. During the adulthood, the connection among neurons in the brain becomes more efficient and numerous than in the childhood brain. As a result, the adult mature brain is equipped to find real relations in diverse perspectives in the highly connected diverse society.

Human sociality is evolved biologically as eusociality. Eusociality (eu in Greek means good) is the highest level of organization of sociality. Ants, bees, and termites are eusocial animals. Originally, eusociality was defined to include organisms (only invertebrates) that had the three features consisting of reproductive division of labor, overlapping generations, and cooperative care of young [29]. These three features can be generalized as interdependent division of labor, multigenerational generativity, and intergroup generosity. With this generalization, human is a species of eusocial ape [27] according to E.O. Wilson. The original human interdependent division of labor involved the interdependent division of labor between hunters and gatherers in the original human hunter-gatherer society. The human multigenerational generativity involves the women's long life after menopause to take care of their grandchildren. The human intergroup generosity involves human natural compassion.

In the identity-adversity development, the adversity is disintegration that fails to find relations independently in diversity in the society. The social instincts against disintegration are alliance with other adults through reciprocity and generativity for multigenerational care. Adults need to use all social instincts to build family in society. For healthy adulthood, the mental countermeasure against disintegration is integration that involves all social instincts and protective instincts. Without integration from all effective social and protective in- 
stincts against disintegration, most mental disorders emerge in late adolescence and early adulthood [78].

\section{The Instinctive Personality Theory}

Personality theories and psychotherapy are unavoidably linked. The proposed instinctive personality theory is based on the social instincts in Section 2 and the protective instincts in Section 3. In the instinctive personality theory, personality can be measured by neurotransmitters, hormones, and the brain activities. The instincts are relatively orthogonal and independent, so the types of personality are also relatively orthogonal and independent. As a result, the instinctive personality theory is the origin of other personality theories.

Some of the popular personality theories are the big five personality traits [79], the MBTI (Myers-Briggs Type Indicator) [80], the social style model [81], the Hofstede's cultural dimensions [82] and the Schwartz's theory of basic human values by Shalom H. Schwartz [83]. The big five personality traits consists of extraversion (assertive, energetic, sociable), agreeableness (cooperative, good-natured, trusting), neuroticism (easily upset, maladjusted, not calm), conscientiousness (dependable, orderly, responsible), and openness to experience (imaginative, independent-minded, intellectual). The opposites are introversion, disagreeableness, calmness, haphazardness, and closeness to experience. The four dimensional MBTI consists of extraversion-introversion, feeling-thinking, sensing-intuition, and perceiving-judging. The two dimensional social style model consists of tell-ask and people-tasks (emotes-controls). The Hofstede's six cultural dimensions include individualism versus collectivism (IDV), power distance index (PDI), masculinity versus femininity (MAS), uncertainty avoidance index (UAI), long term orientation versus short term normative orientation (LTO), and indulgence versus restraint (IVR) to represent differences among national cultures, and each dimension in each national culture is given a numerical index from survey of people in different nations. Such cultural dimensions can be represented by personality dimensions. Another cultural personality theory is the Schwartz's theory of basic human values by Shalom H. Schwartz to measure Universal Values that are recognized throughout all major cultures. The Schwartz's theory identifies ten such motivationally distinct values in the two dichotomies: self-transcendence (benevolence and universalism)/self-enhancement (power and hedonism-achievement) and openness to change (self-direction and stimulation)/conservation (conformity and security-tradition). The paper proposes that the big five personality traits, the MBTI, the social style model, the Hofstede's cultural dimensions, and the Schwartz's theory of basic human values are derived from the instinctive personality theory as in Table 5.

\subsection{Reciprocal Sociality for Alliance vs. Committed Sociality for Kinship}

In Section 2, the base of alliance is reciprocal sociality without commitment. The 
Table 5. The comparison of the personality theories.

\begin{tabular}{|c|c|c|c|c|c|}
\hline Instinctive Personality Theory & Personality Traits & MBTI & Social Style & Hofstede's & Schwartz's \\
\hline reciprocal sociality for alliance & extraversion & extraversion & tells & low PDI & openness to change \\
\hline committed sociality for kinship & (introversion) & introversion & asks & high PDI & conservation \\
\hline collectivistic cooperative-relational ego & agreeableness & feeling & people & low IDV & self-transcendence \\
\hline individualistic competitive-independent ego & (disagreeableness) & thinking & tasks & high IDV & self-enhancement \\
\hline balanced hyperactivity & (calmness) & & & low MAS & \\
\hline overactive hyperactivity (dramatic-impulsive) & neuroticism & & & high MAS & \\
\hline balanced comforter & conscientiousness & judging & & low IVR & \\
\hline overactive comforter (odd-eccentric) & (haphazardness) & perceiving & & high IVR & \\
\hline balanced phobia & openness to experience & intuition & & low UAI & \\
\hline overactive phobia (fearful-anxious) & (closeness to experience) & sensing & & high UAI & \\
\hline high generativity sociality & & & & high LTO & \\
\hline low generativity sociality & & & & low LTO & \\
\hline
\end{tabular}

relationship among allies is changeable reciprocal benefit. Because individuals in alliance have to pay attention to this changeable reciprocal benefit, the individuals appear to be assertive. It is desirable for individuals to have as many allies as possible motivated by pleasurable neurotransmitter endorphins from meeting people, so the individuals appear to be energetic and sociable.

In the big five personality traits and the MBTI, extraversion as assertive, energetic, and sociable is derived from reciprocal sociality for alliance. In the social style model, "tell" indicates the center of attention as the high assertive behavior of extraverts. "Tell" is derived from reciprocal sociality for alliance. In the Hofstede's cultural dimensions, individuals in low Power Distance Index (PDI) with short distances among different levels of hierarchy have liberty to challenge continuously the justification for such hierarchical order. Culturally, low Power Distance is basically liberty. In terms of personality, low PDI represents reciprocal sociality for alliance where relation is unstable, and hierarchy is low. In the Schwartz's theory of basic human values, openness to change is the character of changeable reciprocal sociality in alliance.

The base of kinship is committed sociality rather than reciprocal sociality. The relationship among kin is stable based on commitment. Individuals in kinship do not need to be assertive about their committed sociality, and they simply accept passively committed sociality which is motivated by pleasurable neurotransmitter oxytocin from meeting kin. As a result, the individuals are passive. Because the number of kin in kinship is limited, individuals in kinship are reserved and quiet without the need to actively seek kin.

In the big five personality traits and the MBTI, introversion to be passive, reserved, and quiet is derived from committed sociality for kinship. In the social style model, "ask" (passiveness) indicates outside of the center of attention as the unassertive behavior of introverts. A viable society needs both extroversion trait for alliance and introversion trait for kinship. In the Hofstede's cultural dimensions, people culturally in societies with high Power Distance accept and respect 
such hierarchical order where everybody has a committed role and which needs no further constant justification in such way that everyone is a committed professional in one's hierarchy. Culturally, high Power Distance in the Hofstede's cultural dimensions is basically professional. In terms of personality, high PDI represents committed sociality for kinship where relation is based on committed role instead of reciprocal interest, and hierarchy is high such as parent-child relation. In the Schwartz's theory of basic human values, conservation is the character of commitment in kinship.

\subsection{Collectivistic Cooperative-Relational Ego vs. Individualistic Competitive-Independent Ego}

In Section 2, collectivistic ego is cooperative-relational, while individualistic ego is competitive-independent. In the big five personality traits, agreeableness to be cooperative, good-natured, and trusting is derived from collectivistic cooperative ego, while disagreeableness (antagonism) as the opposite of agreeableness is derived from individualistic competitive ego.

In the MBTI, "feeling" considers the needs of the people involved, so "feeling" is derived from collectivistic relational ego, while "thinking" tends to decide things from a more detached standpoint, so "thinking" is derived from individualistic independent ego. In the social style model, "people" is about relation, so "people" (emotes) is derived from collectivistic relational ego, while "tasks" (controls) is about independent thinking, so "tasks" is derived from individualistic independent ego. In the social style model, asks-tasks is analytical, tells-tasks is driving, asks-people is amiable, and tells-people is expressive. A viable society needs both agreeableness trait for cooperation and relations and disagreeableness trait for competition and independence.

In the Hofstede's cultural dimensions, individualism versus collectivism (IDV), individualism (high IDV) can be defined as a preference for a loosely-knit social framework in which individuals are expected to take care of only themselves and their immediate families. Its opposite, collectivism (low IDV), represents a preference for a tightly-knit framework in society in which individuals can expect their relatives or members of a particular group to look after them in exchange for unquestioning loyalty. In other words, individualism is "I" as individual, while collectivism is "we" as common. In the combination of PDI and IDV for democracy (which literally means in Greek power to all people), the combination of low power distance (low PDI) and individualism (high IDV) produces individual liberal democracy for competitive individual liberty, while the combination of high power distance (high PDI) and collectivism (low IDV) produces common professional democracy commonly known as socialism democracy [84] for cooperative common wellbeing. The potential type index (PTI) is as follows.

$$
\mathrm{PTI}=(\mathrm{IDV}-\mathrm{PDI}) / 2
$$

The high value of PTI represents the high propensity for individual liberal 
democracy, while low value of PTI represents the high propensity for common professional democracy. As a result, PTI identifies the potential of each nation for certain type of democracy. The statistical correlation between PTI and DI (Democracy Index) for liberal democracy [85] results in the best-fit equation. The best-fit equation between PTI and DI and its R2 are shown in Equation (2).

$$
\mathrm{DI}_{\text {expected }}=0.0546 \mathrm{PTI}+7.435 \quad \mathrm{R} 2=0.4
$$

The correlation between PTI and DI is moderate $(\mathrm{R} 2=0.4)$.

In the Schwartz's theory of basic human values, self-transcendence (benevolence and universalism) corresponds to collectivism (cooperation and relation), while self-enhancement (power and hedonism-achievement) corresponds to individualism (competition and independence). One example for theory of basic human value is the study by Ho-Beng Chia et al. for four tigers (Singapore, South Korea, Taiwan (China), and Hong Kong (China)) and the Dragon (China) which are Greater China societies under the strong influence of Confucianism [86]. The study found that despite the differences in political and social-economic factors, all of them have self-transcendence (collectivism) as the highest value among the four values, and all five Greater China societies except South Korea have conservation (committed kinship as professionalism) as the second highest value. As a whole, the values of Greater China societies are in the order of collectivism, committed kinship as professionalism, and individualism = reciprocal alliance as liberty. Professionalism as conservation is shown in International Student Assessment (PISA) as an international assessment that measures 15-year-old students' reading, mathematics, and science literacy every three years. In PISA 2018 [87], children from Greater China societies ranked high in all three subjects. The top five in Mathematics are China, Singapore, Macau (China), Hong Kong (China), and Chinese Taipei. Therefore, Greater China societies are much more suitable for common professional democracy for cooperative common wellbeing than individual liberal democracy for competitive individual liberty. It follows the Confucian tradition that emphasizes the obligations and commitments between emperor and subject, parent and child, husband and wife, older brother and younger brother, and between friend and friend. Covid-19 pandemic is under control in Greater China societies as well as other Confucian countries in East Asia, while Covid-19 pandemic is out of control in most other populous regions as predicted by Corey L Fincher et al. for the enhancement of pathogen transmission by individualism [88]. Different cultural personalities have different comparative advantages under different conditions to establish the interdependent interconnected world among different cultural personalities [19].

\subsection{Balanced Hyperactivity-Regulator against Danger vs. Overactive Hyperactivity against Danger}

In Section 3 for the protective instincts, the mental immune system includes 
hyperactivity countermeasure against danger adversity to maintain existence, comforter countermeasure against hardship adversity to maintain durability, and phobia countermeasure against unfamiliarity-uncertainty adversity to maintain adaptability. In the balanced mental immune system, the mental countermeasure is balanced by the mental immune system regulator, in the same way as the countermeasure in the physical immune system is balanced by the immune system regulator that constrains the activity of the countermeasure. Personality trait involves balanced countermeasure-regulator against adversity vs. overactive countermeasure against adversity.

Balanced hyperactivity-regulator against danger produces calmness (emotional stability) against danger, while overactive hyperactivity against danger produces neuroticism (easily upset, maladjusted, not calm as in dramatic-impulsive cluster personality disorder) against danger in the big five personality traits. A viable society needs both calmness trait for a steady society in a relatively safe environment and neuroticism trait to hyper-activate people for a mobilized society in a relatively dangerous environment.

In the Hofstede's cultural dimensions for Masculinity vs. femininity (MAS), low MAS as a small difference between masculinity and femininity is for cooperation, modesty, caring for the weak, and quality of life, while high MAS as a large difference between masculinity and femininity represents achievement, heroism, assertiveness, and material rewards for success. In terms of personality, low MAS represents calmness in balanced hyperactivity-regulator against danger, while high MAS represents hyperactivity in overactive hyperactivity against danger. People in high MAS culture tends to be very dedicated to work. The original source of high MAS is dangerous environment which requires hyperactive mobilization.

\subsection{Balanced Comforter-Regulator against Hardship vs. Overactive Comforter against Hardship}

Balanced comforter-regulator against hardship produces conscientiousness (dependable, orderly, responsible) in the big five personality traits, while overactive comforter against hardship produces haphazardness as lack of direction (undependable, disorderly, irresponsible as in odd-eccentric cluster personality disorder). A viable society needs conscientiousness trait for a pragmatic society in a relatively well-off environment and haphazardness trait to comfort people for an imaginative society in a relatively harsh environment.

In the MBTI, "judging" prefers to complete organized and structured assignments, so "judging" is like "conscientiousness in the big five personality traits, and is derived from balanced comforter-regulator against hardship. "Perceiving" prefers exciting and flexible ideas, so "perceiving" is like "haphazardness" in the big five personality traits, and is derived from overactive comforter against hardship.

In the Hofstede's cultural dimensions for Indulgence vs. Restraint (IVR), Restraint (low IVR), reflects a conviction that relatively free gratification of basic 
and natural human desires needs to be curbed and regulated by strict social norms. Its opposite pole, Indulgence (high IVR) stands for a tendency to allow relatively free gratification of basic and natural human desires related to enjoying life and having fun. In terms of personality, Restraint is like conscientiousness that represents balanced comforter-regulator against hardship, while Indulgence is like haphazardness that represents overactive comforter against hardship.

\subsection{Balanced Phobia-Regulator against Unfamiliarity-Uncertainty vs. Overactive Phobia against Unfamiliarity-Uncertainty}

For the big five personality traits, balanced phobia-regulator against unfamiliarity-uncertainty produces openness to experience (imaginative, independent-minded, and intellectual), while overactive phobia against unfamiliarity-uncertainty produces closeness to experience (traditional, dogmatic-minded, and closed-minded as in fearful-anxious cluster personality disorder). A viable society needs openness to experience trait for an open society in a relatively familiar-certain environment and closeness to experience trait to isolate people for a protective society in a relatively unfamiliar-uncertain environment. Different viable societies need different personality traits from different social and protective instincts for different societies under different environments.

In the MBTI, "intuition" is non-routine new intuition, so "intuition" is like "openness to experience" in the big five personality traits, and is derived from balanced phobia-regulator against unfamiliarity-uncertainty, while "sense" is routine concrete sense, so "sense" is like "closeness to experience" in the big five personality traits, and is derived from overactive phobia against unfamiliarity-uncertainty. As a result, extraversion, agreeableness, conscientiousness, and openness to experience in the big five personality traits are correlated to extraversion-introversion, thinking-feeling, judging-perceiving, and sensing-intuition, respectively in the MBTI, which is in agreement with the correlational analysis between the big five personality traits and the MBTI from a total of 900 participants [89].

In the Hofstede's cultural dimensions for the uncertainty avoidance index (UAI), high UAI is uncertainty avoidance, while low UAI is uncertainty tolerance. Societies with uncertainty avoidance prefer clearly defined codes of behavior, guidelines, and laws based on absolute truth. Societies with uncertainty tolerance accept and even welcome different thoughts or ideas and free-flowing environments. In personality, uncertainty tolerance is like openness to experience that represents balanced phobia-regulator against unfamiliarity-uncertainty, while uncertainty avoidance is like closeness to experience that represents overactive phobia against unfamiliarity-uncertainty.

\subsection{High Generativity Sociality for Multigenerational Care vs. Low Generativity Sociality for Multigenerational Care}

Multigenerational relation benefits future generations by forming multigenera- 
tional group whose relations depend on generativity sociality. Culturally, generativity is represented by long-term orientation in the Hofstede's cultural dimensions. In long term orientation versus short term normative orientation (LTO), long-term orientation (high LTO) represents thrift for being sparing with resources, persistence for sustained efforts for slow results, willingness to subordinate oneself for a purpose, and concern with personal adaptiveness, while short-term orientation (low LTO) represents social pressure toward spending, efforts to produce quick results, concern with social and status obligations, and concern with personal stability. The top positions for LTO are occupied by China and Japan and the Four Little Dragons (Hong Kong (China), Taiwan (China), South Korea, and Singapore). These countries are under the influence of Confucianism. Continental European countries occupied a middle range. Great Britain and its Anglo partners Australia, New Zealand, the United States, and Canada scored on the short-term side.

The combination of MAS, IVR, UAI, and LTO produces the potential workforce index (PWI) as follows [84].

$$
\mathrm{PWI}=(\mathrm{MAS}-\mathrm{IVR}-\mathrm{UAI}+\mathrm{LTO}) / 2
$$

With some adjustments for inevitable fast GDP growth rate (growth spurt) for young economy in developing countries and inevitable slow GDP growth rate for mature economy in developed countries, the statistical correlation between PWI and GR (GDP Growth Rate between 2010 and 2019 [90] produces the best-fit equation and R2 value. The best-fit equation between PWI and GR and its $\mathrm{R} 2$ are shown as follows.

$$
\mathrm{GR}_{\text {expected }}=0.0457 \mathrm{PWI}+2.2094 \quad \mathrm{R} 2=0.8
$$

The correlation between PWI and GR is strong $(\mathrm{R} 2=0.8)$. PTI (potential type index) has no correlation with GR. Among the five personality theories, the Hofstede's cultural most closely match with the instinctive personality theory.

Other possible personality traits from the social instincts in Section 2 are from reproductive sociality for propagation, interdependent sociality for division of labor, and territorial dualistic ego. Reproductive sociality can be tested from sexual orientation and gender differences. Interdependent sociality can be tested from the test for theory of mind [91]. Interdependent sociality also relates to versatility in the social style model to recognize the social styles of other people and make informed choices about how to best interact with them [81]. Territorial dualistic ego can be tested from the rigidity of perceived boundary in dualism and the absence of universal values without boundary.

Personality tests reveal individuals' predispositions in the social and protective instincts, so people know better who they are. Personality tests provide self-assessment (the pursuit of accurate self-knowledge), self-enhancement (the pursuit of favorable self-knowledge) and self-verification (the pursuit of highly certain self-knowledge) [92]. Self-knowledge provides an opportunity to self-manage according to individual's capabilities and preferences. In terms of mental health 
maintenance, the personality tests allow people to avoid the extremes of their personalities and to understand and get along with people from different personalities. Cultural personality allows nations to have self-knowledge who they are among different cultural personalities. As different personal personalities have different comparative advantages under different conditions, different cultural personalities have different comparative advantages under different conditions. No one personal personality should be excluded from an interconnected and diverse society, so no one cultural personality should be excluded in the highly interconnected and diverse world, and no one cultural personality should be hegemonic. All nations with different cultural personalities must respect and understand instead of villainize different motivations from different cultural personalities, and work together under common goals.

\section{Wakefulness and Sleep}

Sleep is important for survival. Dream in sleep is important in psychoanalysis. According Freud [3], the content of dream explains the unconscious mind which is inaccessible through waking conscious. The manifest content of dream consists of the elements of actual images, thoughts, and content within the dream. The latent content of the dream elucidates the hidden meaning of one's unconscious thoughts, drives, and desires behind the manifest content of dream. Freud proposed four mechanisms, condensation, displacement, and secondary revision, to obscure latent dream. Condensation reduces and simplifies rich contents of latent dream. Displacement substitutes various aspects in constituents, intensity, significance, and properties of manifest and latent dream to render them dissimilar. Symbols expresses dream by relevant signs. Secondary revision makes disordered and incoherent dream materials well-organized and reasonable which are quite different from its actual implication.

Freud regarded dreams as a royal road to the unconscious, so dream interpretation has been an important psychoanalytic technique. Dream in sleep is more than a royal road to the unconscious. Sleep reactivates, consolidates, and stabilizes wakeful memories during wakefulness. Wakefulness, sleep, and hallucination are listed in Table 6.

\subsection{Wakefulness}

The brainstem and the cortex in wakefulness are active. Wakefulness has voluntary bodily movement. The connection between the hippocampus for the storage of episodic memory and the neocortex for the other memories is open. The open connection between hippocampus and neocortex allows both episodic memory and procedural memory to consolidate.

Plasticity is the availability for new neural connection for consolidation and stabilization of memory as determined by the high amount of glutamine neurotransmitter with respect to GABA neurotransmitter [93]. Stability is opposite to plasticity. During wakefulness, stability is greater than plasticity in order to 
Table 6. Wakefulness, sleep, and hallucination.

\begin{tabular}{|c|c|c|c|c|c|c|c|}
\hline State/simulation & Brainstem & Cortex & $\begin{array}{l}\text { Voluntary } \\
\text { bodily } \\
\text { movement }\end{array}$ & $\begin{array}{l}\text { Hippocampus } \\
\text { neocortex }\end{array}$ & $\begin{array}{l}\text { Plasticity/ } \\
\text { stability }\end{array}$ & $\begin{array}{c}\text { Consolidation } \\
\text { of episodic/procedural } \\
\text { memories }\end{array}$ & Memory input \\
\hline wakefulness & active & $\begin{array}{l}\text { active } \\
\text { (alpha-beta } \\
\text { waves) }\end{array}$ & active & $\begin{array}{l}\text { open } \\
\text { hippocampus } \leftrightarrow \\
\text { neocortex }\end{array}$ & $\begin{array}{l}\text { plasticity }< \\
\text { stability }\end{array}$ & episodic $=$ procedural & $\begin{array}{l}\text { sensory } \\
\text { experiences }\end{array}$ \\
\hline $\begin{array}{l}\text { light NREM/light } \\
\text { basking }\end{array}$ & hypoactive & $\begin{array}{l}\text { hypoactive with } \\
\text { occasional } \\
\text { surges (some } \\
\text { spindle waves) }\end{array}$ & inactive & $\begin{array}{l}\text { open } \\
\text { hippocampus } \leftrightarrow \\
\text { neocortex }\end{array}$ & $\begin{array}{l}\text { plasticity > } \\
\text { stability }\end{array}$ & episodic $>$ procedural & $\begin{array}{l}\text { waking } \\
\text { memory }\end{array}$ \\
\hline $\begin{array}{l}\text { deep NREM/deep } \\
\text { basking }\end{array}$ & hypoactive & $\begin{array}{l}\text { hypoactive with } \\
\text { few surges } \\
\text { (mostly slow } \\
\text { waves) }\end{array}$ & inactive & $\begin{array}{l}\text { open hippocampus } \\
\leftrightarrow \text { neocortex }\end{array}$ & $\begin{array}{l}\text { mostly } \\
\text { downscale } \\
\text { for recovery }\end{array}$ & $\begin{array}{l}\text { episodic and } \\
\text { suppress procedural }\end{array}$ & $\begin{array}{l}\text { waking } \\
\text { memory }\end{array}$ \\
\hline $\begin{array}{l}\text { tonic REM/light } \\
\text { death-feigning }\end{array}$ & active & $\begin{array}{l}\text { active } \\
\text { (alpha-beta } \\
\text { waves) }\end{array}$ & inactive & $\begin{array}{l}\text { disrupted } \\
\text { hippocampus } \leftrightarrow \\
\text { neocortex } \\
\text { (space-time } \\
\text { dissolution) }\end{array}$ & $\begin{array}{l}\text { plasticity }< \\
\text { stability }\end{array}$ & episodic $<$ procedural & $\begin{array}{l}\text { NREM } \\
\text { memory }\end{array}$ \\
\hline $\begin{array}{l}\text { phasic REM/deep } \\
\text { death-feigning }\end{array}$ & hyperactive & $\begin{array}{l}\text { hyperactive } \\
\text { (gamma waves) }\end{array}$ & inactive & $\begin{array}{l}\text { disrupted } \\
\text { hippocampus } \leftrightarrow \\
\text { neocortex } \\
\text { (space-time } \\
\text { dissolution) }\end{array}$ & $\begin{array}{l}\text { plasticity }< \\
\text { stability }\end{array}$ & episodic $<$ procedural & $\begin{array}{l}\text { NREM } \\
\text { memory }\end{array}$ \\
\hline $\begin{array}{l}\text { therapeutic } \\
\text { psychedelic } \\
\text { hallucination }\end{array}$ & active & $\begin{array}{l}\text { hyperactive } \\
\text { (dosage } \\
\text { dependent) }\end{array}$ & $\begin{array}{l}\text { under } \\
\text { therapeutic } \\
\text { control }\end{array}$ & $\begin{array}{l}\text { disrupted } \\
\text { hippocampus } \leftrightarrow \\
\text { neocortex } \\
\text { (space-time } \\
\text { dissolution) }\end{array}$ & $\begin{array}{l}\text { plasticity > } \\
\text { stability }\end{array}$ & $\begin{array}{l}\text { mostly emotional } \\
\text { procedural }\end{array}$ & $\begin{array}{l}\text { waking } \\
\text { therapeutic } \\
\text { advises and } \\
\text { trainings }\end{array}$ \\
\hline
\end{tabular}

avoid the easy replacement of old memory by new memory [94]. It is still possible to consolidate memory by rehearse. The input for memory is sensory experiences and new thought.

\subsection{Light NREM}

Sleep can be divided into NREM (non-rapid eye movement) stage and REM stage. NREM can be further divided into light NREM and deep NREM. Light NREM can again is divided into N1 and N2. N1 appears at the beginning of sleep followed by N2. N1 is not repeated, while N2 is repeated several times afterward. It is the longest stage as about $50 \%$ of sleep. Light NREM is a simulation of light basking for cold blood reptile to warm up in a very relaxing manner as proposed by Rial et al. [95]. The EEG patterns in NREM are similar to the EEG patterns in the basking state. Mostly likely, light NREM and light basking evolve independently for night and day, respectively.

NREM has a low activity in the brain stem and thalamus [96]. The cortex is also hypoactive with occasional surges of activity shown in sleep wave as spindle 
waves. The voluntary bodily movement in NREM is inactive. Masako Tamaki et al. found the complementary contributions of NREM and REM sleep to visual learning [93]. NREM contributes the plasticity of memory, while REM contributes the stabilization of memory. During NREM, plasticity with glutamine is greater than stability with GABA, so the consolidation of memory is greater than the stabilization of memory. The connection between hippocampus and neocortex is open. According to Wei, Krishnan, and Bazhenov, an interaction between hippocampal input and synaptic plasticity leads to consolidation of memories during NREM [97]. The connection between hippocampus and neocortex is open. The hypoactive cortex consolidates mostly episodic memory originated from the hippocampus.

Sleep is an isolated mental activity with little outside interference, so the input of memory during sleep is from new waking memory which has not completely consolidated and stabilized. Sleep without outside interference is a much better time to the reactivation, consolidation, and stability of waking memories than wakefulness with continuous outside interferences.

\subsection{Deep NREM}

Light NREM is followed by deep NREM which is the simulation of deep basking. The body is very hypoactive. The mind is also very hypoactive with few surges of activity. Unlike light NREM, deep NREM is also the time to recovery from bodily activity and memory activity such as consolidation of memory, so deep NREM is downscale for recovery. While few surges of activity allow the consolidation of episodic memory, the downscale actually suppresses procedural memory as shown by Andrillon et al. in the formation and suppression of acoustic memories during human sleep [98]. The suppression removes irrelevant and non-adaptive memories to have more room for new memory as proposed by Langille [99]. Deep NREM is required for sufficient energy to reactivate, consolidate, and stabilize waking memories [100].

\subsection{Tonic REM}

REM is the simulation of death-feigning. According to Tsoukalas [101], REM sleep is a simulation of death-feigning as the last line of defense against an attacking predator by the total immobilization of the animal. The neurophysiology and phenomenology of this reaction shows striking similarities to REM sleep. REM and death-feigning likely evolve independently for night and day, respectively. There is no rapid eye movement in tonic REM. The mind is active with the similar EEG as in wakefulness. REM sleep is punctuated and immediately preceded by PGO (ponto-geniculo-occipital) waves, bursts of electrical activity originating in the brain stem [102].

The connection between the hippocampus and the neocortex is disrupted by cortisol and acetylcholine to stop the output from hippocampus [103]. The hippocampus contains episodic memory which refers to knowledge about the past 
that incorporates information about where and when particular events occurred. The neocortex contains semantic memory and procedural memory, which consist of knowledge and skill that have been uncoupled from place and time [104]. The disruption without the output from hippocampus leads the dissolution of space and time [103]. According to the self-organization theory by Zhang and Guo, the sleeping brain is a self-organizing system that can combine discontinuous and incongruous neuronal signals (i.e. different elements of dreams) without space and time into a relatively continuous narrative during sleep [105]. Consequently, dream in REM has no realistic sequence of space and time, going from one place to another place and from one time to another time unrealistically. The self-organization theory allows the therapist to derive important information (e.g. significant memories) from dream content and underscores emotions as a potential order parameter that can provide an effective means of grasping the core of a dream. Therefore, dream analysis may still prove useful in the therapeutic process.

With active cortex and brain stem, procedural memory is more active than episodic memory. Stabilization with GABA is greater than consolidation with glutamine. Light REM basically stabilizes the NREM memory, mostly episodic NREM memory.

\subsection{Phasic REM}

Phasic REM is the simulation of deep death-feigning. The brainstem is hyperactive. There is rapid eye movement. The cortex is hyperactive more active than normal wakefulness. Like tonic REM, the voluntary bodily movement is inactive. The connection between the hippocampus and the neocortex is disrupted, resulting in the dissolution of space and time. The dreams in phasic REM are much more colorful than the dreams in tonic REM [106]. It consolidates and stabilizes emotional NREM procedural memory.

\subsection{Therapeutic Psychedelic Hallucination}

Psychedelics are a class of psychoactive substances, which induce profoundly altered states of consciousness, including transient and dose-dependent distortions as hallucinations in the subjective experience of one's self. Recently, psilocybin has been studied extensively for therapeutic psychedelic hallucination [107]. During therapeutic psychedelic hallucination, the voluntary bodily movement is active, but is under therapeutic (clinical) control with restricted movement. The brainstem and the cortex are hyperactive depending on the dosages of psilocybin. The connection between hippocampus and neocortex is disrupted by no glutamine for hippocampus and high amount of glutamine for neocortex, so there is the dissolution of space and time resulting in hallucination [108]. The hallucination is like lucid dream [109]. The high amount of glutamine in neocortex produces high plasticity for procedural memory [110]. Such high plasticity for procedural memory allows the consolidation of the beneficial memory of 
therapeutic advises and trainings during wakefulness without hallucination. This therapeutic psychedelic hallucination is useful to cure addiction and anxiety disorder.

\section{Psychotherapy and Mental Health Maintenance}

Personality-mental disorders are disordered behavioral habits. Psychoanalysis that intends to find the source of disorders from unconscious is slow to normalize disordered behavioral habits for serious mental problems without repetitive training in normalizing disordered behavioral habits. Effective therapies normalize such disordered behavioral habits by effective therapeutic skills through repetitive training in normalizing cognitions, feelings, and behaviors as in CBT through therapeutic explicit memory, and by effective therapeutic conscious attention to disordered behavioral habits as in mindfulness meditation through repetitive training in therapeutic conscious attention.

Many different types of psychotherapy for adult depression have been developed. Some of them are different variations of psychoanalysis, CBT, and mindfulness meditation. Pim Cuijpers et al. did a metaanalysis to examine the effects of 15 different types of psychotherapy for depression [111]. The 15 types of psychotherapy are basically the different variations of psychoanalysis, CBT, and mindfulness meditation. The variations of psychoanalysis include brief problem-solving therapy, extended problem-solving therapy, self-examination therapy, full interpersonal therapy, brief interpersonal therapy, and life review therapy. The variations of CBT include pleasant activity scheduling, contextual behavioral activation, and acceptance and commitment therapy. The combination of cognition therapy and mindfulness meditation is mindfulness-based cognitive therapy (MBCT) [112]. The evaluation of the effects is not conclusive because of high levels of heterogeneity, publication bias, and the risk of bias in the majority of studies. The conclusion is that the 15 types of psychotherapy may be effective in the treatment of depression.

For the religious people who believe strongly the divine participation in life, the strong divine participation exists in their thoughts, feelings, and behaviors. In the Abrahamic religions (Judaism, Christianity, and Islam), God is assumed implicitly or explicitly as heavenly parent, while the believers are God's children. As a result of such strong divine participation, the instinctive mental countermeasures and regulators in the protective mental immune system are replaced by divine mental countermeasures and regulators in the religious mental immune system [113] as in Table 7.

In the religious mental immune system, comforter instinctive countermeasure against hardship is replaced by divine love countermeasure against hardship. Overactive divine love results in religious odd-eccentric cluster in the constant need of divine love in terms of comforter against ubiquitous perceived hardship. Hyperactivity instinctive countermeasure against danger is replaced by divine power countermeasure against danger. Overactive divine power results in 
Table 7. The religious mental immune system.

\begin{tabular}{|c|c|c|c|c|}
\hline Adversity & $\begin{array}{c}\text { Instinctive } \\
\text { Mental } \\
\text { Countermeasure }\end{array}$ & $\begin{array}{c}\text { Religious } \\
\text { Mental } \\
\text { Countermeasure }\end{array}$ & $\begin{array}{l}\text { Religious } \\
\text { Mental } \\
\text { Regulator }\end{array}$ & Religious Personality Disorder \\
\hline Hardship & comforter & divine love & $\begin{array}{l}\text { divine } \\
\text { providence }\end{array}$ & overactive divine love $=$ religious odd-eccentric cluster \\
\hline Danger & Hyperactivity & divine power & $\begin{array}{l}\text { divine } \\
\text { providence }\end{array}$ & $\begin{array}{l}\text { overactive divine power }=\text { religious dramatic-impulsive } \\
\text { cluster }\end{array}$ \\
\hline Unfamiliarity-Uncertainty & Phobia & divine authority & $\begin{array}{l}\text { divine } \\
\text { providence }\end{array}$ & $\begin{array}{l}\text { overactive divine authority }=\text { religious fearful-anxious } \\
\text { cluster }\end{array}$ \\
\hline
\end{tabular}

religious dramatic-impulsive cluster in the constant need of divine power in terms of hyperactivity against ubiquitous perceived danger. Phobia instinctive countermeasure against unfamiliarity-uncertainty is replaced by divine authority against unfamiliarity-uncertainty. Overactive divine authority results in religious fearful-anxious cluster in the constant need of divine authority in terms of phobia against ubiquitous perceived unfamiliarity-uncertainty.

The divine regulator for all these religious disorders is the divine providence (intervention) for ubiquitous perceived adversities. The divine providence for ubiquitous perceived adversities includes the divine long-term plan, the divine control, the divine community support, and the specific divine revelation. The divine long-term plan includes the return of Israel nation under God in the future for Judaism and the Heaven in afterlife for Christianity and Islam. Different specific long-term planes are for different specific believers in this life. Under the divine long-term plan, ubiquitous perceived adversities are temporary. The divine control is that everything is under divine control for the good of believers openly or secretly. For an example for Christians, "And we know that in all things God works for the good of those who love him, who have been called according to his purpose (Romans 8:28). Under the divine control, ubiquitous perceived adversities are under the divine control even though it is hard to understand. The divine community support comes from the love among believers. For an example in the Jesus' commend to his disciples, "My command is this: Love each other as I have loved you" (John 15:12). People who suffer from the ubiquitous perceived adversities have the divine community support. The specific divine revelation is different for different people. For an example, Martin Luther as a monk who suffered from depression due to his ubiquitous perceived unforgiven sins as ubiquitous perceived dangers found the specific revelation in "the righteous shall live by faith" (Romans 1:17) to cure his ubiquitous perceived unforgiven sins through righteousness by faith. Different people find different specific divine revelations to cure their ubiquitous perceived adversities.

The divine providence changes negative thought patterns into positive though patterns. Repetitive training in normalizing thought patterns, feelings, and behaviors normalize personality-mental disorders. According to Simon Dein, the evidence suggests that, on balance, religious involvement is generally conductive 
to better mental health, and patients with psychiatric disorders frequently use religion to copy with their distresses [114]. The religious therapy and CBT are combined into religiously integrated cognitive behavioral therapy (RCBT) [115].

Since mental health involves both psychotherapy and mental health maintenance, the four-component mind can be used to establish mental health routines for mental health maintenance. Two of the routines for mental health maintenance to minimize social stress are compassion meditation and perspective-taking meditation from the ReSource Project at the Max Planck Institute for Human Cognitive and Brain Sciences in Leipzig [116] [117]. Compassion meditation concentrated on compassion and emotional connection via loving kindness meditations and non-judgmental problem-sharing sessions with a partner. Perspective-taking meditation encouraged people to think about issues from different points of view, also via a mix of partnered sessions and solo meditation. Compassion-based meditation showed increases in the limbic system, which processes emotions, and the anterior insula, which helps bring emotions into conscious awareness. Perspective-taking meditation boosted regions involved in theory of mind. After the training, participants were asked to give a presentation at short notice, resulting in a stressful situation. Both groups showed up to a 51 per cent drop in cortisol levels compared with controls. The compassion meditation and perspective-taking meditation minimize social stress from the fear of being judged harshly or falling short of expectations.

Mindfulness meditation was also studied in the ReSource Project. Mindfulness meditation made people calmer to minimize impulsiveness, but did not minimize social anxiety. Different routines for mental health maintenance serve different purposes. All major religions have religious routines (meditations) and teachings to maintain mental health within supporting and coherent religious communities. According to Harold Koenig, religion and spirituality may help people better cope or exacerbate their stress, covering its relationship to depression, anxiety, suicide, substance abuse, well-being, happiness, life satisfaction, optimism, generosity, gratitude and meaning and purpose in life [118]. Both religious and non-religious routines are important for mental health maintenance as long as they respect one another to maintain personal mental health and social peace.

\section{Summary and Conclusions}

In summary, this paper proposes that conscious, explicit memory, implicit memory, and instincts constitute the four-component mind for the mental origins of psychotherapy and personality. The unconscious instincts consist of the six social instincts for the formation of society and the three protective instincts against adversities. The six social instincts are kinship instinct based on commitment, alliance instinct based on reciprocity, division of labor based on interdependence, reproductive (sexual) instinct based on propagation, generativity instinct based on multigenerational care, and boundary instinct based on the 
boundary between ingroup and outgroup. The three egos based on boundary instinct are dualistic territorial ego with rigid boundary, competitive-independent individualistic ego without rigid boundary and with extended outgroup, and cooperative-relational collectivistic ego without rigid boundary and with extended ingroup.

The three protective instincts that contain the three countermeasures against the three adversities are hyperactivity countermeasure against danger, phobia countermeasure against unfamiliarity-uncertainty, and comforter countermeasure against hardship. Each countermeasure is regulated (moderated) by a regulator to minimize overactive countermeasure as physical regulator to minimize overactive immunity in physical immune system. Severe adversities and ineffective regulators over-activate protective countermeasures to generate overactive countermeasures as overactive hyperactivity, overactive phobia, and overactive comforter, corresponding to dramatic-impulsive cluster, anxious-fearful cluster, and odd-eccentric cluster, respectively for personality-mental disorders in the DSM-5.

The unconscious six social and three mental protective instincts are the bases of the proposed instinctive personality theory which is the mental origin of the personality theories including the big five personality traits, the MBTI, the social style model, the Hofstede's cultural dimensions, and the Schwartz's theory of basic human values. Among the five personality theories, the Hofstede's cultural dimensions are most closely match with the instinctive personality theory.

Memory includes sensory memory, short-term (working) memory, explicit memory, and implicit memory. Conscious is controlled mostly by sensory memory and short-term (working) memory. For psychotherapy, implicit memory contains basically behavioral habit memory. Disordered behavioral habits for personality-mental disorders are stored in disordered behavioral habit memory in implicit memory. For the survival of the normal mental state, explicit memory and conscious attention (working memory) automatically and instinctively become therapeutic explicit memory and therapeutic conscious attention to normalize disordered behavioral habit memory. The failure to normalize leads to the damage in explicit memory and conscious For psychotherapy, cognitive behavioral therapy (CBT) normalizes disordered thought patterns in explicit memory to normalize disordered behavioral habit memory in implicit memory through the repetitive training in normalizing thought patterns, feelings, and behaviors. Mindfulness meditation strengthens conscious attention to normalize disordered behavioral habit memory through the repetitive training in directing conscious attention to the breath or body. Both CBT and mindfulness-based therapy are effective to treat mental problems.

This paper proposes identity-adversity development consisting of infancy, toddlerhood, childhood, and adulthood. Each stage has its principal identity, process of principal identity, attribute, process of attribute, principal adversity and countermeasure, and potential personality disorder. In infancy, the principal identity is parent and the process for parent-identity is parent-recognition. The 
attribute is trust, and the process for trust-attribute is trust in parent. The social instincts are kinship instinct and boundary instinct. The adversity is danger with hyperactivity countermeasure. The potential mental problem is dramatic-impulsive cluster. In toddlerhood, the principal identity is self and the process for self-identity is self-recognition. The attribute is autonomy, and the process for autonomy-attribute is exploration. The adversity is unfamiliarity-uncertainty with phobia countermeasure during the exploration. The potential mental problem is fearful-anxious cluster. In childhood, the principal identity is other people, and the process for the other-people-identity is theory of mind to learn diverse perspectives. The attribute is diversity, and the process for diversity-attribute is learning. The adversity is hardship with comforter countermeasure. The potential mental problem is odd-eccentric cluster. In adulthood, the principal identity is society, and the process for society-identity is sociality to establish relations in diversity. The attribute is eusociality, and the process for eusociality is interdependent division of labor, multigenerational generativity, and intergroup generosity. The social instincts are alliance, sexual, and generativity. The adversity is disintegration that fails to find relations in diversity, and the countermeasure is integration to find relations in diversity. The mental problems start to emerge during early adulthood.

Sleep reactivates, consolidates, and stabilizes wakeful memories during wakefulness. Sleep consists of light NREM, deep NREM, tonic REM, and phasic REM. Wakefulness, the stages of sleep, and the therapeutic psychedelic hallucination are different in brainstem activity, cortex activity, voluntary bodily movement, the path between the hippocampus and the neocortex, plasticity vs. stability, episodic vs. procedural memory consolidation, and memory input. This therapeutic psychedelic hallucination is useful to cure addiction and anxiety disorder by the increase of plasticity in procedural memory.

Current types of psychotherapy are the variations of psychoanalysis, CBT, and mindfulness meditation. According to a metaanalysis to examine the effects of various different types of psychotherapy for depression, they may be effective in the treatment of depression. The religion with the strong divine participation replaces the instinctive mental immune system with the religious mental immune system with its own religious therapy for mental disorders. Religious therapy can be incorporated with CBT to form RCBT. Both religious and non-religious routines are important for mental health maintenance as long as they respect one another to maintain personal mental health and social peace.

In conclusion, the mental origin of personality-mental disorders is from the overactive protective instincts. The mental origin of psychotherapy is from therapeutic implicit memory and conscious attention for CBT and mindfulness meditation, respectively. The mental origin of the personality theories including the big five personality traits, the MBTI, the social style model, the Hofstede's cultural dimensions, and the Schwartz's theory of basic human values is from the unconscious instincts (the six social and three mental protective instincts). The 
mental origin of psychological development is also from the unconscious instincts (the six social and three mental protective instincts). Therefore, the four-component mind of conscious, explicit memory, implicit memory, and instincts explains the origin, the storage, and the normalization of personality-mental disorders for psychotherapy, and provides the mental origins for psychological development and personality.

\section{Conflicts of Interest}

The author declares no conflicts of interest regarding the publication of this paper.

\section{References}

[1] Freud, S. (1916-1917) Introductory Lectures on Psycho-Analysis. In: Strachey, J., Ed., The Standard Edition of the Complete Psychological Works of Sigmund Freud, Vols. XV \& XVI, The Hogarth Press, London, 2195-2549.

[2] Freud, S. (1905) Three Essays on the Theory of Sexuality. In: Strachey, J., Ed., The Standard Edition of the Complete Psychological Works of Sigmund Freud, Vol. 7, The Hogarth Press, London, 1457-1552.

[3] Freud, S. (1900) The Interpretation of Dreams. In: Strachey, J., Ed., The Standard Edition of the Complete Psychological Works of Sigmund Freud, Vol. 1, The Hogarth Press, London, 507-1098.

[4] Schacter, D. (1987) Implicit Memory: History and Current Status. Journal of Experimental Psychology: Learning, Memory, and Cognition, 13, 501-518. https://doi.org/10.1037/0278-7393.13.3.501

[5] Roth, R., Baribeau, J., Milovan, D. and O'connor, K. (2004) Procedural and Declarative Memory in Obsessive-Compulsive Disorder. Journal of the International Neuropsychological Society, 10, 647-654. https://doi.org/10.1017/S1355617704105018

[6] Kempton, M., et al. (2011) Structural Neuroimaging Studies in Major Depressive Disorder: Meta-Analysis and Comparison with Bipolar Disorder. Archives of General Psychiatry, 68, 675-690. https://doi.org/10.1001/archgenpsychiatry.2011.60

[7] Nairne, J., Thompson, S. and Pandeirada, J. (2007) Adaptive Memory: Survival Processing Enhances Retention. Journal of Experimental Psychology: Learning, Memory, and Cognition, 33, 263-273. https://doi.org/10.1037/0278-7393.33.2.263

[8] Brown, K., Goodman, R., Ryan, R. and Anālayo, B. (2016) Mindfulness Enhances Episodic Memory Performance: Evidence from a Multimethod Investigation. PLoS ONE, 11, e0153309. https://doi.org/10.1371/journal.pone.0153309

[9] Samuelson, K. (2011) Post-Traumatic Stress Disorder and Declarative Memory Functioning: A Review. Dialogues in Clinical Neuroscience, 13, 346-351. https://doi.org/10.31887/DCNS.2011.13.2/ksamuelson

[10] Ullman, M. and Pullman, M. (2015) A Compensatory Role for Declarative Memory in Neurodevelopmental Disorders. Neuroscience and Biobehavioral Reviews, 51, 205-222. https://doi.org/10.1016/j.neubiorev.2015.01.008

[11] Bartfeld, R.A. (2016) From Squirrels to Cognitive Behavioral Therapy (CBT): The Modulation of the Hippocampus. The Science Journal of the Lander College of Arts and Sciences, 10, 14-23.

[12] Bailey, N., Freedman, G., Raj, K., et al. (2020) Mindfulness Meditators Show Enhanced Accuracy and Different Neural Activity during Working Memory. Mind- 
fulness, 11, 1762-1781. https://doi.org/10.1007/s12671-020-01393-8

[13] Teasdale, J., Segal, S., Williams, J., et al. (2000) Prevention of Relapse/Recurrence in Major Depression by Mindfulness-Based Cognitive Therapy. The Journal of Consulting and Clinical Psychology, 68, 615-623. https://doi.org/10.1037/0022-006X.68.4.615

[14] Boyd, J., Lanius, R. and McKinnon, M. (2018) Mindfulness-Based Treatments for Posttraumatic Stress Disorder: A Review of the Treatment Literature and Neurobiological Evidence. Journal of Psychiatry \& Neuroscience: JPN, 43, 7-25. https://doi.org/10.1503/jpn.170021

[15] Hölzel, B., Hoge, E., Greve, D., et al. (2013) Neural Mechanisms of Symptom Improvements in Generalized Anxiety Disorder Following Mindfulness Training. NeuroImage: Clinical, 2, 448-458. https://doi.org/10.1016/j.nicl.2013.03.011

[16] Landgraf, S., Steingen, J., Eppert, J., Niedermeyer, U., der Meer, E. and Kruegar, F. (2011) Temporal Information Processing in Short- and Long-Term Memory of Patients with Schitzophrenia. PLOS ONE, 6, e26140. https://doi.org/10.1371/journal.pone.0026140

[17] Landré, L., et al. (2012) Working Memory Processing of Traumatic Material in Women with Post Traumatic Stress Disorder. Journal of Psychiatry \& Neuroscience, 37, 87-94. https://doi.org/10.1503/jpn.100167

[18] Chung, D. (2018) The Mental Protection System for Protective Behaviors: The Social Brain and the Mental Immune System. Journal of Behavioral and Brain Science, 8, 31-55. https://doi.org/10.4236/jbbs.2018.81003

[19] Chung, D. (2020) Premodernity, Modernity, Postmodernity, and Eu-Modernity as the Four Stages of Civilizational Developmental Psychology: Comte's Parallel Human-Civilizational Developments. Advances in Applied Sociology, 10, 369-420. https://doi.org/10.4236/aasoci.2020.109023

[20] Dunbar, R. (2016) The Social Brain Hypothesis and Human Evolution. In: Oxford Research Encyclopedia of Psychology, Oxford University Press, Oxford, 1-33. https://doi.org/10.1093/acrefore/9780190236557.013.44

[21] Frith, C. (2007) The Social Brain? Philosophical Transactions of the Royal Society B: Biological Sciences, 362, 671-678. https://doi.org/10.1098/rstb.2006.2003

[22] Cozolino, L. (2006) The Neuroscience of Human Relationships: Attachment and the Developing Social Brain. W. W. Norton \& Co., New York.

[23] Hamilton, W. (1964) The Genetical Evolution of Social Behavior II. Journal of Theoretical Biology, 7, 17-52. https://doi.org/10.1016/0022-5193(64)90039-6

[24] Shultz, S. and Dunbar, R. (2007) The Evolution of the Social Brain: Anthropoid Primates Contrast with Other Vertebrates. Proceeding of Royal Society B, 274, 2429-2436. https://doi.org/10.1098/rspb.2007.0693

[25] Dunbar, R. (1993) Coevolution of Neocortex Size, Group Size and Language in Humans. Behavioral and Brain Sciences, 16, 681-735. https://doi.org/10.1017/S0140525X00032325

[26] Hill, K. (2011) Co-Residence Patterns in Hunter-Gatherer Societies Show Unique Human Social Structure. Science, 331, 1286-1289. https://doi.org/10.1126/science.1199071

[27] Wilson, E.O. (2012) The Social Conquest of the Earth. W. W. Norton \& Company, New York.

[28] Chung, D. (2016) The Basic Principles of Kin Sociality and Eusociality: Human Evolution. Natural Science, 8, 8-19. https://doi.org/10.4236/ns.2016.81002 
[29] Crespi, B.J. and Douglas, Y. (1995) The Definition of Eusociality. Behavior Ecology, 6, 109-115. https://doi.org/10.1093/beheco/6.1.109

[30] Chung, D. (2016) The Human Religious Evolution. Open Journal of Social Sciences, 4, 75-90. https://doi.org/10.4236/jss.2016.43013

[31] Heyes, C. (2015) Animal Mindreading: What's the Problem? Psychonomic Bulletin \& Review, 22, 313-327. https://doi.org/10.3758/s13423-014-0704-4

[32] Stoléru, S. (2014) Reading the Freudian Theory of Sexual Drives from a Functional Neuroimaging Perspective. Fronties in Human Neuroscience, 8, 157. https://doi.org/10.3389/fnhum.2014.00157

[33] Hull, E., et al. (2004) Dopamine and Serotonin: Influences on Male Sexual Behavior. Physiology and Behavior, 83, 291-307. https://doi.org/10.1016/j.physbeh.2004.08.018

[34] Nagaraj, A., et al. (2009) Antipsychotics and Sexual Dysfunction Sexual Dysfunction Part III. Online Journal of Health and Allied Sciences, 8, 1. http://www.ojhas.org/issue31/2009-3-1.htm

[35] Magon, N. and Kalra, S. (2011) The Orgasmic History of Oxytocin: Love, Lust, and Labor. Indian Journal of Endocrinology and Metabolism, 15, S156-S161. https://doi.org/10.4103/2230-8210.84851

[36] Erikson, E. and Erikson, J. (1998) The Life Cycle Completed. W. W. Norton \& Company, New York.

[37] Slater, C. (2003) Generativity versus Stagnation: An Elaboration of Erikson's Adult Stage of Human Development. Journal of Adult Development, 10, 53-65. https://doi.org/10.1023/A:1020790820868

[38] McAdams, D. and De St. Aubin, E. (1992) A Theory of Generativity and Its Assessment through Self-Report, Behavioral Acts, and Narrative Themes in Autobiography. Journal of Personality and Social Psychology, 62, 1003-1015. https://doi.org/10.1037/0022-3514.62.6.1003

[39] Chung, D. (2018) The Eight Stages of Psychosocial Protective Development: Developmental Psychology. Journal of Behavioral and Brain Science, 8, 369-398. https://doi.org/10.4236/jbbs.2018.86024

[40] Finch, C. and Stanford, C. (2004) Meat-Adaptive Genes and the Evolution of Slower Aging in Humans. The Quarterly Review of Biology, 79, 3-50. https://doi.org/10.1086/381662

[41] Kim, P., Coxworth, J. and Hawkes, K. (2012) Increased Longevity Evolves from Grandmothering. Proceedings of the Royal Society B: Biological Sciences, 279, 4880-4884. https://doi.org/10.1098/rspb.2012.1751

[42] Turner, J. and Reynolds, K. (2010) The Story of Social Identity. In: Postmes, T. and Branscombe, N., Eds., Rediscovering Social Identity: Core Sources, Psychology Press, New York, 13-32.

[43] Cohen, T., Montoya, R. and Insko, C. (2006) Group Morality and Intergroup Relations: Cross-Cultural and Experimental Evidence. Personality and Social Psychology Bulletin, 32, 1559-1572. https://doi.org/10.1177/0146167206291673

[44] Shultz, T., Hartshorn, M. and Kaznatcheev, A. (2009) Why Is Ethnocentrism More Common than Humanitarianism? Proceedings of the 31 st Annual Conference of the Cognitive Science Society 2010-2015, Austin, TX.

[45] Hamlin, J., Mahajan, N. and Wynn, K. (2013) Not Like Me = Bad Infants Prefer Those Who Harm Dissimilar Others. Psychological Science, 24, 589-594.

https://doi.org/10.1177/0956797612457785 
[46] Wrangham, R. (2018) Two Types of Aggression in Human Evolution. Proceedings of the National Academy of Sciences, 115, 245-2534. https://doi.org/10.1073/pnas.1713611115

[47] Nesdale, D. and Duffy, A. (2011) Social Identity, Peer Group Rejection, and Young Children's Reactive, Displaced, and Proactive Aggression. British Journal of Developmental Psychology, 29, 823-841. https://doi.org/10.1111/j.2044-835X.2010.02012.x

[48] Tulogdi, A., et al. (2010) Brain Mechanisms Involved in Predatory Aggression Are Activated in a Laboratory Model of Violent Intra-Specific Aggression. European Journal of Neuroscience, 32, 1744-1753. https://doi.org/10.1111/j.1460-9568.2010.07429.x

[49] Tulogdi, A., et al. (2015) Neural Mechanisms of Predatory Aggression in RatsImplications for Abnormal Intraspecific Aggression. Behavioural Brain Research, 283, 108-115. https://doi.org/10.1016/j.bbr.2015.01.030

[50] Wilson, M., et al. (2014) Lethal Aggression in Pan Is Better Explained by Adaptive Strategies than Human Impacts. Nature, 513, 414-417.

https://doi.org/10.1038/nature13727

[51] McDonald, M. (2012) Evolution and the Psychology of Intergroup Conflict: The Male Warrior Hypothesis. Personality and Social Psychology Bulletin, 32, 1559-1572.

[52] Leonard, B. (2010) The Concept of Depression as a Dysfunction of the Immune System. Current Immunology Reviews, 6, 205-212.

https://doi.org/10.2174/157339510791823835

[53] Szałach, Ł.P., Lisowska, K.A. and Cubała, W.J. (2019) The Influence of Antidepressants on the Immune System. Archivum Immunologiae et Therapiae Experimentalis, 67, 143-151. https://doi.org/10.1007/s00005-019-00543-8

[54] American Psychiatric Association (2013) Diagnostic and Statistical Manual of Mental Disorders. 5th Edition, American Psychiatric Publishing, Arlington. https://doi.org/10.1176/appi.books.9780890425596

[55] Boecker, H., et al. (2008) The Runner's High: Opioidergic Mechanisms in the Human Brain. Cerebral Cortex, 18, 2523-2531. https://doi.org/10.1093/cercor/bhn013

[56] Taylor, M. (1999) Imaginary Companions and the Children Who Create Them. Oxford University Press, New York.

[57] Taylor, M., Hulette, A. and Dishion, T. (2010) Longitudinal Outcomes of Young High-Risk Adolescents with Imaginary Companions. Developmental Psychology, 46, 1632-1636. https://doi.org/10.1037/a0019815

[58] Feusner, J., Townsend, J., Bystritsky, A. and Bookheimer, S. (2007) Visual Information Processing of Faces in Body Dysmorphic Disorder. Archives of General Psychiatry, 64, 1417-1425. https://doi.org/10.1001/archpsyc.64.12.1417

[59] Sperry, L. and Sperry, J. (2016) Cognitive Behavioral Therapy of DSM-5 Personality Disorders: Assessment, Case Conceptualization, and Treatment. 3rd Edition, Routledge/Taylor \& Francis Group, Oxfordshire. https://doi.org/10.4324/9780203764084

[60] Cowan, N. (2008) Chapter 20 What Are the Differences between Long-Term, Short-Term, and Working Memory? Essence of Memory, Progress in Brain Research, 169, 323-338. https://doi.org/10.1016/S0079-6123(07)00020-9

[61] Kumaran, D. (2008) Short-Term Memory and the Human Hippocampus. Journal of Neuroscience, 28, 3837-3838. https://doi.org/10.1523/JNEUROSCI.0046-08.2008

[62] Lara, A. and Wallis, J. (2015) The Role of Prefrontal Cortex in Working Memory: A Mini Review. Frontiers in Systems Neuroscience, 9, 173. 
https://doi.org/10.3389/fnsys.2015.00173

[63] Funahashi, S. (2017) Working Memory in the Prefrontal Cortex. Brain Sciences, 7, 49. https://doi.org/10.3390/brainsci7050049

[64] Graf, P. and Schacter, D. (1985) Implicit and Explicit Memory for New Associations in Normal and Amnesic Subjects. Journal of Experimental Psychology. Learning, Memory, and Cognition, 11, 501-518. https://doi.org/10.1037/0278-7393.11.3.501

[65] Szpunar, K. (2010) Episodic Future Thought. Perspectives on Psychological Science, 5, 142-162. https://doi.org/10.1177/1745691610362350

[66] Scoville, W. and Milner, B. (1957) Loss of Recent Memory after Bilateral Hippocampal Lesions. Journal of Neurology, Neurosurgery, and Psychiatry, 20, 11-21. https://doi.org/10.1136/jnnp.20.1.11

[67] Foerde, K., Knowlton, B. and Poldrack, R. (2006) Modulation of Competing Memory Systems by Distraction. Proceedings of the National Academy of Sciences of the United States of America, 103, 11778-11783.

https://doi.org/10.1073/pnas.0602659103

[68] McBride, D., Thomas, B. and Zimmerman, C. (2013) Test of the Survival Processing Advantage in Implicit and Explicit Memory Tests. Memory \& Cognition, 41, 862-871. https://doi.org/10.3758/s13421-013-0304-y

[69] Libet, B., Gleason, C., Wright, E., et al. (1983) Time of Conscious Intention to Act in Relation to Onset of Cerebral Activity (Readiness Potential). Brain, 106, 623-642. https://doi.org/10.1093/brain/106.3.623

[70] Lush, P., et al. (2016) Metacognition of Intentions in Mindfulness and Hypnosis. Neuroscience of Consciousness, 2016, niw007. https://doi.org/10.1093/nc/niw007

[71] Lazar, S., et al. (2005) Meditation Experience Is Associated with Increased Cortical Thickness. Neuroreport, 16, 1893-1897. https://doi.org/10.1097/01.wnr.0000186598.66243.19

[72] Hogan, J. and Vaccaro, T. (2006) Internationalizing the History of Developmental Psychology. New York University Press, New York.

[73] Peters, R. (2006) Ageing and the Brain. Postgraduate Medical Journal, 82, 84-88. https://doi.org/10.1136/pgmj.2005.036665

[74] Mancia, M. (2006) Implicit Memory and Early Unrepressed Unconscious: Their Role in the Therapeutic Process How the Neurosciences Can Contribute to Psychoanalysis. The International Journal of Psychoanalysis, 87, 83-103. https://doi.org/10.1516/D43P-8UPN-X576-A8V0

[75] Tsutaya, T. and Yoneda, M. (2013) Quantitative Reconstruction of Weaning Ages in Archaeological Human Populations Using Bone Collagen Nitrogen Isotope Ratios and Approximate Bayesian Computation. PLoS ONE, 8, e72327. https://doi.org/10.1371/journal.pone.0072327

[76] Bogin, B. and Varea, C. (2016) Evolution of Human Life History. In: Kaas, J., Ed., Evolution of Nervous Systems, Elsevier, Amsterdam, 37-50. https://doi.org/10.1016/B978-0-12-804042-3.00103-2

[77] Taylor, M., et al. (2004) The Characteristics and Correlates of Fantasy in School-Age Children: Imaginary Companions, Impersonation, and Social Understanding. Developmental Psychology, 40, 1173-1187. https://doi.org/10.1037/0012-1649.40.6.1173

[78] Kessler, R., et al. (2007) Age of Onset of Mental Disorders: A Review of Recent Literature. Current Opinion in Psychiatry, 20, 359-364.

https://doi.org/10.1097/YCO.0b013e32816ebc8c 
[79] Goldberg, L. (1993) The Structure of Phenotypic Personality Traits. American Psychologist, 48, 26-34. https://doi.org/10.1037/0003-066X.48.1.26

[80] Myers, I. and Myers, P. (1995) Gifts Differing: Understanding Personality Type. Davies-Black Publishing, Mountain View.

[81] Merrill, D. and Reid, R. (1999) Personal Styles and Effective Performance. CRC Press, New York.

[82] Hofstede, G., et al (2010) Cultures and Organizations: Software of the Mind. McGraw-Hill, London.

[83] Schwartz, S. (2012) An Overview of the Schwartz Theory of Basic Values. Online Readings in Psychology and Culture, 2. https://doi.org/10.9707/2307-0919.1116

[84] Chung, D. (2020) General Marxism by Production Dimension Model, Production Evolution, and Individualism-Collectivism Duality. Open Journal of Social Sciences, 8, 282-336. https://doi.org/10.4236/jss.2020.86025

[85] The Economist Intelligence Unit (2020) Democracy Index 2019. https://www.eiu.com/topic/democracy-index

[86] Chia, H., et al. (2007) Four Tigers and the Dragon: Values Differences, Similarities, and Consensus. Asia Pacific Journal of Management, 24, 305-320.

https://doi.org/10.1007/s10490-006-9033-0

[87] OECD (2019) PISA 2018 Results. https://www.oecd.org/pisa/publications/pisa-2018-results.htm

[88] Fincher, C., et al. (2008) Pathogen Prevalence Predicts Human Cross-Cultural Variability in Individualism/Collectivism. Proceeding of Royal Society B, 275, 1279-1285. https://doi.org/10.1098/rspb.2008.0094

[89] Furnham, A., Moutafi, J. and Crump, J. (2003) The Relationship between the Revised Neo-Personality Inventory and the Myers-Briggs Type Indicator. Social Behavior and Personality, 31, 577-584. https://doi.org/10.2224/sbp.2003.31.6.577

[90] Ventura, L. (2019) Countries with Highest GDP Growth 2019. Global Finance Magazine, April 24, 2019.

https://www.gfmag.com/global-data/economic-data/countries-highest-gdp-growth

[91] Wellman, H. and Liu, D. (2004) Scaling of Theory-of-Mind Tasks. Child Development, 75, 523-541. https://doi.org/10.1111/j.1467-8624.2004.00691.x

[92] Sedikides, C. (1993) Assessment, Enhancement, and Verification Determinants of the Self-Evaluation Process. Journal of Personality and Social Psychology, 65, 317-338. https://doi.org/10.1037/0022-3514.65.2.317

[93] Tamaki, M., et al. (2020) Complementary Contributions of Non-REM and REM Sleep to Visual Learning. Nature Neuroscience, 23, 1-7.

https://doi.org/10.1038/s41593-020-0666-y

[94] Dubue, J., McKinney, T., Treit, D. and Dickson, C. (2015) Intrahippocampal Anisomycin Impairs Spatial Performance on the Morris Water Maze. Journal of Neuroscience, 35, 11118-11124. https://doi.org/10.1523/JNEUROSCI.1857-15.2015

[95] Rial, R., et al. (2010) Evolution of Wakefulness, Sleep and Hibernation: From Reptiles to Mammals. Neuroscience and Biobehavioral Reviews, 34, 1144-1160. https://doi.org/10.1016/j.neubiorev.2010.01.008

[96] Thanh, T., et al. (2010) Functional Neuroimaging Insights into the Physiology of Human Sleep. Sleep, 33, 1589-1603. https://doi.org/10.1093/sleep/33.12.1589

[97] Wei, Y., Krishnan, G. and Bazhenov, M. (2016) Synaptic Mechanisms of Memory Consolidation during Sleep Slow Oscillations. Journal of Neuroscience, 36, 4231-4247. 
https://doi.org/10.1523/JNEUROSCI.3648-15.2016

[98] Andrillon, T., Pressnitzer, D., Léger, D. and Kouider, S. (2017) Formation and Suppression of Acoustic Memories during Human Sleep. Nature Communications, 8, Article No. 179. https://doi.org/10.1038/s41467-017-00071-z

[99] Langille, J. (2019) Remembering to Forget: A Dual Role for Sleep Oscillations in Memory Consolidation and Forgetting. Frontiers in Cellular Neuroscience, 13, 71. https://doi.org/10.3389/fncel.2019.00071

[100] Fattinger, S., et al. (2017) Deep Sleep Maintains Learning Efficiency of the Human Brain. Nature Communications, 8, Article No. 15405.

https://doi.org/10.1038/ncomms15405

[101] Tsoukalas, I. (2012) The Origin of REM Sleep: A Hypothesis. Dreaming, 22, 253-283. https://doi.org/10.1037/a0030790

[102] Steriade, M. and McCarley, R. (1990) Brainstem Control of Wakefulness and Sleep. Springer, New York, 263-282. https://doi.org/10.1007/978-1-4757-4669-3_9

[103] Payne, J. and Nadel, L. (2004) Sleep, Dreams, and Memory Consolidation: The Role of the Stress Hormone Cortisol. Learning \& Memory, 11, 671-678. https://doi.org/10.1101/lm.77104

[104] Tulving, E. (1983) Elements of Episodic Memory. Oxford University Press, London.

[105] Zhang, W. and Guo, B. (2018) Freud's Dream Interpretation: A Different Perspective Based on the Self-Organization Theory of Dreaming. Frontier Psychology, 9, 1553. https://doi.org/10.3389/fpsyg.2018.01553

[106] Hodoba, D., et al. (2007) Dream Recall after Night Awakenings from Tonic/Phasic REM Sleep. Collegium Antropologicum, 32, 69-73.

[107] Nour, M., Evans, L., Nutt, D. and Carhart-Harris, R. (2016) Ego-Dissolution and Psychedelics: Validation of the Ego-Dissolution Inventory (EDI). Frontiers in $\mathrm{Hu}$ man Neuroscience, 10, 269. https://doi.org/10.3389/fnhum.2016.00269

[108] Mason, N., Kuypers, K., Müller, F., et al. (2020) Me, Myself, Bye: Regional Alterations in Glutamate and the Experience of Ego Dissolution with Psilocybin. Neuropsychopharmacology, 45, 2003-2011. https://doi.org/10.1038/s41386-020-0718-8

[109] Kraehenmann, R. (2017) Dreams and Psychedelics Neurophenomenological Comparison and Therapeutic Implications. Current Neuropharmacology, 15, 1032-1042. https://doi.org/10.2174/1573413713666170619092629

[110] Carhart-Harris, R. and Nutt, D. (2017) Serotonin and Brain Function a Tale of Two Receptors. Journal of Psychopharmacology, 31, 1091-1120. https://doi.org/10.1177/0269881117725915

[111] Cuijpers, P., Karyotaki, E., de Wit, L. and Ebert, D. (2020) The Effects of Fifteen Evidence-Supported Therapies for Adult Depression: A Meta-Analytic Review. Psychotherapy Research, 30, 279-293. https://doi.org/10.1080/10503307.2019.1649732

[112] Evans, S., Ferrando, S., Findler, M., et al. (2008) Mindfulness-Based Cognitive Therapy for Generalized Anxiety Disorder. Journal of Anxiety Disorders, 22, 716-721. https://doi.org/10.1016/j.janxdis.2007.07.005

[113] Chung, D. (2019) The Evolution of Theisms: The Four Technological Revolutions and the Four Theistic Revolutions. Open Journal of Social Sciences, 7, 213-242. https://doi.org/10.4236/jss.2019.74018

[114] Dein, S. (2010) Religion Spirituality and Mental Health. Psychiatric Times, 27, 28-32.

https://www.psychiatrictimes.com/view/religion-spirituality-and-mental-health

[115] Pearce, M., et al. (2015) Religiously Integrated Cognitive Behavioral Therapy: A 
New Method of Treatment for Major Depression in Patients with Chronic Medical Illness. Psychotherapy, 52, 56-66. https://doi.org/10.1037/a0036448

[116] Valk, S., et al. (2017) Structural Plasticity of the Social Brain: Differential Change after Socio-Affective and Cognitive Mental Training. Science Advances, 3, E1700489. https://doi.org/10.1126/sciadv.1700489

[117] Veronika, E., et al. (2017) Specific Reduction in Cortisol Stress Reactivity after Social But Not Attention-Based Mental Training. Science Advances, 3, E1700495. https://doi.org/10.1126/sciadv.1700495

[118] Koenig, H. (2018) Religion and Mental Health: Research and Clinical Applications. Academic Press, Cambridge. 